\title{
IDENTIFICANDO DERECHOS FUNDAMENTALES EN LA CONSTITUCIÓN ESPAÑOLA
}

\author{
IDENTIFYING FUNDAMENTAL RIGHTS IN THE SPANISH \\ CONSTITUTION
}

\author{
ANTONIO IBÁÑEZ MaCíAS \\ Universidad de Cádiz
}

Fecha de recepción: 19-2-19

Fecha de aceptación: 17-12-19

Resumen: En este trabajo se ofrecen algunos criterios o reglas interpretativas simples para contribuir a la identificación de los derechos fundamentales en la Constitución española, cuestión que sigue siendo polémica en la doctrina constitucional. De acuerdo con esas reglas interpretativas, hallamos derechos fundamentales no sólo en el Capitulo II del Título I de la Constitución española, sino también en el Capítulo III, en el Capítulo I, e incluso fuera del Título I de la Constitución. A todos los derechos identificados hay que aplicarles las consecuencias lógicas del carácter de norma fundamental de la Constitución. En consecuencia, vinculan a todos los poderes públicos, incluidos el poder legislativo y el poder judicial.

Abstract: In this paper we offer some simple interpretative criteria or rules to contribute to the identification of fundamental rights in the Spanish Constitution, question that remains controversial in the constitutional doctrine. In accordance with these rules, we find fundamental rights not only in Chapter II of Title I of the Spanish Constitution, but also in Chapter III, in Chapter I, and even outside Title I of the Constitution. All the rights identified must apply to them the logical consequences of the character of the fundamental norm of the Constitution. Consequently, they bind all public authorities, including the legislator and the judiciary.

Palabras clave: derechos fundamentales, Constitución española, interpretación, identificación

Keywords: fundamental rights, Spanish Constitution, interpretation, identification 


\section{INTRODUCCIÓN}

Cuarenta años después de la entrada en vigor de la Constitución, sigue siendo un cuestión polémica, no definitivamente zanjada, la determinación de cuáles son los derechos fundamentales en la Constitución española, en especial en relación con los enunciados normativos del Capítulo III de la CE. Para contribuir al debate, vamos a ofrecer algunos criterios o reglas interpretativas sencillas, procurando regirnos por los principios de claridad, simplicidad y coherencia. La primera regla (R1) tiene el propósito de establecer una definición formal de derecho fundamental, como equivalente a derecho constitucional y extraer las consecuencias del mismo. La siguientes tres reglas pretenden identificar "derechos" en la Constitución española, y combinadas con la regla R1, permiten deducir qué son derechos fundamentales. La regla R2 se basa en el criterio de la interpretación literal. Aquí ofrecemos argumentos para superar los obstáculos que representan los artículos 53.1 y 53.2 CE. La regla R3 atiende al concepto de derecho subjetivo, y su relación con los conceptos, propios de la lógica jurídica, de "permisión" y de "facultad", para proceder a identificar poderes explícitos o implícitos reconocidos por la Constitución a los particulares. Las dos últimas reglas se basan en la correlación lógica que existe entre los conceptos de "derecho y "deber" -u "obligación" - (regla R4) y, consecuentemente, entre los conceptos de "derecho" y "prohibición" (regla derivada RD 4.1).

Hemos sometido las reglas interpretativas a formulación en el lenguaje de la lógica simbólica porque esto ayuda a ver con más claridad sus implicaciones lógicas. Hemos usado la lógica relacional y de predicados, sin cuantificadores (al tratarse de reglas generales, presuponemos que se emplea siempre el cuantificador universal). Los símbolos utilizados son, para las variables individuales, $x, y, z$; para los predicados, una letra mayúscula; para las conectivas lógicas, los siguientes: la negación, ; la conjunción, $\wedge$; la disyunción incluyente, $v$; la disyunción excluyente, $w$; la implicación, $\rightarrow$; la coimplicación, $\leftrightarrow$.

\section{REGLA UNO: SOLO CUANDO UN DERECHO SE RECONOCE EN LA CONSTITUCIÓN, ES UN DERECHO FUNDAMENTAL}

A los fines de nuestro estudio, utilizaremos un concepto puramente formal de derecho fundamental ${ }^{1}$. Es el concepto más amplio posible de derecho

1 Es el modelo positivista de fundamentación de los derechos fundamentales. Véase: I. FERNÁNDEZ SARASOLA, "Modelos históricos de fundamentación de los derechos", en 
fundamental en la Constitución española (en adelante, CE), no atiende a su contenido o naturaleza, ni a su ubicación en el texto constitucional ni a su nivel de protección (ambas cuestiones relacionadas con el sistema de garantías diseñado en el artículo 53), simplemente a que el derecho se contenga o no en la norma suprema.

Con esta concepción formal (positivista si se quiere) de los derechos fundamentales no pretendemos negar su fundamentación moral en la idea de dignidad humana ${ }^{2}$, ni su origen histórico debido a las aportaciones de al menos tres concepciones ideológicas: la liberal, la democrática y la socialista $^{3}$. En este sentido, suele citarse la definición de derecho fundamental dada por Pérez Luño: derechos fundamentales son “aquellos derechos humanos garantizados por el ordenamiento jurídico positivo, en la mayor parte de los casos en su normativa constitucional, y que suelen gozar de una tutela reforzada" 4 . Al respecto, se ha dicho que: "Los derechos fundamentales son los derechos humanos constitucionalizados" 5 .

Por tanto, podemos decir que: si, y solo si, algo es un derecho y está constitucionalizado (esto es, incluido en la Constitución), entonces ese algo es un derecho fundamental. A esta primera regla la llamaremos $R 1$ y la formularemos del siguiente modo.

$$
R 1:\left(D x^{\wedge} C x\right) \leftrightarrow F x
$$

Se lee: "Si, y solo si, ' $x$ ' es un derecho [Dx], y ' $x$ ' está constitucionalizado [Cx], entonces ' $x$ ' es un derecho fundamental $[F x]$ ".

De la regla R1 se deduce, a contrario sensu, que si un derecho no está constitucionalizado, no es un derecho fundamental. Es decir, se deduce la regla derivada RD1.1: $\left(D x^{\wedge} \sim C x\right) \rightarrow \sim F x$. No existen más derechos fundamentales que

AAVV. Teoría general de los derechos fundamentales en la Constitución española de 1978, Tecnos, Madrid, pp. 18 y ss., esp., p. 24 y ss.

2 Véase, al respecto, G. PECES-BARBA MARTÍNEZ, G., R. ASIS ROIG y M. C. BARRANCO AVILÉS, Lecciones de Derechos Fundamentales, Editorial Dikynson, Madrid, 2004, p. 35 .

3 G. PECES-BARBA MARTíNEZ, G., R. ASIS ROIG y M. C. BARRANCO AVILÉS, Lecciones de Derechos Fundamentales, cit., pp. 129 y ss.

4 A. E. PÉREZ LUÑO, Los derechos fundamentales, Tecnos, Madrid, 1988, p. 46.

5 J. TAJADURA TEJADA, Los derechos fundamentales y sus garantías, Tirant lo Blanch, Valencia, 2015, p. 25. 
los establecidos en la Constitución ${ }^{6}$. Como es sabido, la regla del artículo 10.2 $\mathrm{CE}^{7}$ permite interpretar derechos existentes en la $\mathrm{CE}$ de acuerdo con los tratados y declaraciones sobre derechos humanos ratificados por España, pero no crear nuevos derechos fundamentales a partir de los tratados (Entre otras, STC 36/1991). No obstante, cabe entender que, cuando una Constitución, para establecer su catálogo de derechos fundamentales, se remite a declaraciones de derechos o tratados internacionales, tales declaraciones y tratados han quedado constitucionalizados por la remisión.

Como las demás normas constitucionales, las que reconocen derechos son indisponibles por el legislador. En efecto, se dice que hay dos rasgos que caracterizan a los derechos fundamentales: uno es su indisponibidad por el legislador y otro su tutela judicial directa ${ }^{8}$, tal como se reconoce en

6 En este sentido, R. NARANJO DE LA CRUZ, “El sistema de derechos constitucionales y sus garantías", en M. AGUDO ZAMORA y otros. Manual de Derecho Constitucional, Tecnos, $7^{\mathrm{a}}$ ed, Madrid, 2016, pp. 427-458, esp. p. 428.

7 Artículo 10.2 CE: "Las normas relativas a los derechos fundamentales y a las libertades que la Constitución reconoce se interpretarán de conformidad con la Declaración universal de Derechos Humanos y los tratados y acuerdos internacionales sobre la misma materia ratificados por España".

8 Sobre estas dos características de los derechos fundamentales, véase, entre otros: P. CRUZ VILLALÓN, "Formación y evolución de los derechos fundamentales", Revista Española de Derecho Constitucional, 1989, núm. 25, pp. 35-62, esp., p. 41; y en “Derechos fundamentales", en M. ARAGÓN REYES y C. AGUADO RENEDO (dir.), Temas básicos de Derecho Constitucional. Tomo III. Derechos fundamentales y su protección, Editorial Aranzadi. 2. ${ }^{a}$ edición. Navarra, 2011, pp. 23-27, esp., p. 26; J. JIMÉNEZ CAMPO, “Artículo 53. Protección de los derechos fundamentales", en O. ALZAGA VILLAAMIL, Comentarios a la Constitución española de 1978. Tomo IV, Artículos 39 a 55, Edersa, Madrid, 1996, pp. 439 y ss., esp. pp. 443 y 448 , y en Derechos fundamentales: concepto y garantías. Editorial Trotta, Madrid, 1999, p. 17; L. M. DİEZPICAZO, "Capítulo IV. De las garantías de las libertades y derechos fundamentales", en O. ALZAGA VILLAAMIL (dir.). Comentarios a la Constitución española de 1978, Tomo IV, Artículos 39 a 55, Edersa, Madrid, 1996, pp. 425 y ss., esp., p. 429, y en: Sistema de Derechos Fundamentales, Editorial Aranzadi, $2^{a}$ Ed., Pamplona, 2005, p. 37; J. J. SOLOZÁBAL ECHAVARRÍA, "Los derechos fundamentales en la Constitución española". Revista de Estudios políticos, 1999, núm. 105, pp. 9-28, esp. p. 12; y en "Una revisión de la teoría de los derechos fundamentales". Revista jurídica Universidad Autónoma de Madrid, 2001, núm. 4, pp. 105-121. esp., p. 107; F. BASTIDA FREIJEDO, "Capítulo 1. Concepto y modelos históricos de los derechos fundamentales". en F. BASTIDA FREIJEDO, I. VILLAVERDE MENÉNDEZ, P. REQUEJO RODRÍGUEZ, M. A. PRESNO LINERA, B. ALÁEZ CORRAL, I. FERNÁNDEZ SARASOLA, Teoría general de los derechos fundamentales en la Constitución española de 1978, Tecnos, Madrid, 2004, pp. 17 ss., esp. 30 ss. y en “¿Son los derechos sociales derechos fundamentales?”, en R. ALEXY y otros. Derechos sociales y ponderación, Fundación Coloquio Jurídico Europeo, Madrid, 2007, pp. 103150, esp., p. 116); G. ESCOBAR ROCA, "Presupuestos estructurales”, en G. ESCOBAR ROCA 
la Constitución. Pues bien, lo determinante, a nuestro juicio, es la primera característica, que se deduce simplemente del hecho de que el derecho está reconocido en la Constitución. En cambio, la efectividad de la tutela judicial (aunque sea teóricamente directa) va a depender de la naturaleza del derecho en cuestión y, con ello, del grado de su desarrollo legislativo. Si se trata de un derecho de libertad como la libertad de expresión (otros derechos de libertad como la propiedad requieren leyes reguladoras), en principio podrá ser tutelado directamente ante los tribunales tal como se reconoce en la Constitución, incluso en defecto de ley reguladora (omisión legislativa total). En cambio, si se trata de un derecho de configuración legal, es decir, de un derecho cuyo contenido debe ser necesariamente concretado por el legislador ${ }^{9}$, como los llamados derechos sociales de prestación ${ }^{10}$, la tutela judicial podrá ser teóricamente directa (el derecho se puede alegar ante los tribunales tal como lo reconoce la Constitución), pero no efectiva, tal como exige el art. 24 $\mathrm{CE}$, sin desarrollo legislativo del derecho. Por poner algunos ejemplos de derechos que se ubican en la Sección Primera del Capítulo II del Título I, y que tienen el mayor nivel de protección constitucional (no se duda de su carácter fundamental de acuerdo con el sistema de garantías), no se puede ejercer de forma efectiva el derecho al sufragio activo (aunque lo reconozca un juez) sin leyes que organicen las elecciones, ni el derecho a la educación sin leyes que

(ed.). Derechos sociales y tutela antidiscriminatoria, Editorial Aranzadi, Pamplona, 2012, pp. 285306, esp. p. 290; y en "Tema 21. Los derechos humanos y los derechos fundamentales", EN J. M. ${ }^{a}$ CASTELLÀ ANDREU (ed.), Derecho Constitucional Básico, Huygens Editorial. 3. a edición, Barcelona, 2016, pp. 419-441, esp. p. 428.

9 Sobre el concepto de derecho de configuración legal, véase: J. L. REQUEJO PAGÉS, “Derechos de configuración legal (voz)” en Enciclopedia Jurídica Básica, vol. I, Civitas, Madrid, 1995, p. 2385.

10 Precisamente, contra el carácter de derechos fundamentales de los derechos sociales de prestación en general, se ha alegado, entre otras consideraciones, que los derechos sociales no son indisponibles por el legislador ni son justiciables ante los tribunales. Parece que estos argumentos ya han sido suficientemente rebatidos por la doctrina. Véase, al respecto: R. ALEXY, Teoría de los derechos fundamentales, traducción de E. Garzón Valdés. Centro de Estudios Constitucionales, Madrid, p. 496; A. BALDASARRE, Los derechos sociales, traducción de Santiago Perea Latorre, Universidad Externado de Colombia, 2001, pp. 194-197; V. ABRAMOVICH, Y CH. COURTIS, Los derechos sociales como derechos exigibles, Trotta, Madrid, 2002, pp. 21 y ss.; G. PISARELLO, Los derechos sociales y sus garantías. Elementos para una reconstrucción, Trotta, Madrid, 2007, pp. 60 y ss.; G. ESCOBAR ROCA, "Presupuestos estructurales", cit., 2012, pp. 298-303; R. GARCIAA MANRIQUE, La libertad de todos. Una defensa de los derechos sociales, El Viejo Topo, Barcelona, 2013, pp. 150-204; M. C. BARRANCO AVILÉS, “Una defensa de la constitucionalización de los derechos sociales", Derechos y Libertades, núm. 35, pp. 111-135.

ISSN: 1133-0937

DOI: https://doi.org/10.20318/dyl.2021.5856
DERECHOS Y LIBERTADES

Número 44, Época II, enero 2021, pp. 277-315 
organicen la prestación del correspondiente servicio público, ni el derecho a la tutela judicial efectiva sin las leyes procesales pertinentes.

Pero de aquí no podemos deducir que los anteriores derechos no sean auténticos derechos fundamentales sino "meros cometidos constitucionales", pues son derechos claramente contenidos en la Constitución y, por ello mismo, preservados por ésta contra el legislador ${ }^{11}$.

Lo determinante, a nuestro juicio, para que un derecho sea fundamental, es que el derecho se pueda defender ante un órgano jurisdiccional (ordinario o constitucional) incluso contra su ley reguladora. Por ejemplo, en nuestro ordenamiento, la persona interesada podrá formular alegaciones para que el juez plantee la cuestión de inconstitucionalidad ante el Tribunal Constitucional (art. 163 $\mathrm{CE}$ ), o los órganos legitimados podrán plantear el correspondiente recurso de inconstitucionalidad contra la ley de desarrollo del derecho (art. 162.1 a) CE).

Precisamente por su indisponibilidad por el legislador, todos los derechos constitucionales son fundamentales. No pueden existir derechos fundamentales no constitucionalizados, ni derechos constitucionales no fundamentales. Sin embargo, no se exige, como veremos al explicar la regla 2, que el derecho esté reconocido expresamente en la Constitución, sino que se entiende implícitamente constitucionalizado si se puede deducir de uno o varios enunciados normativos constitucionales.

El Tribunal Constitucional ha acogido la doctrina de que sólo los derechos constitucionales son fundamentales, pero con el único propósito de marcar la diferencia respecto de los derechos recogidos en los Estatutos de Autonomías, que no son fundamentales. En efecto, en la Sentencia 247/2007, FJ. 16, el TC declara, respecto de los derechos fundamentales: “Derechos, por tanto, que no se reconocen en la Constitución por ser fundamentales, sino que son tales, justamente, por venir proclamados en la norma que es expresión de la voluntad constituyente. Los derechos reconocidos en los Estatutos

11 Por ello, no podemos compartir la opinión de Böckenförde cuando, al explicar “la teoría de los derechos fundamentales del Estado social", concluye que: "Los derechos fundamentales son reducidos en su dimensión social a meros cometidos del legislador" -E. W. BÖCKENFÖRDE, Escritos sobre derechos fundamentales, prólogo de F. J. Bastida, Trad. de J. L. Requejo Pagés e I. Villaverde Menéndez, Nomos-Verl.-Ges, Baden-Baden, 1993, p. 66-. Son más que eso: por su mero reconocimiento constitucional, dichos derechos (incluso los derechos sociales prestacionales) quedan preservados frente al acción limitadora del legislador. Como dice Alexy, "los derechos fundamentales son posiciones tan importantes que su otorgamiento o no otorgamiento no puede quedar en manos de la simple mayoría parlamentaria" (R. ALEXY, Teoría de los derechos fundamentales, cit., p.432). 
de Autonomía han de ser, por tanto, cosa distinta". Sin embargo, este puede ser un punto de partida para que el Alto Tribunal empiece a incorporar la interpretación que aquí exponemos.

\section{REGLA DOS: SI LA CONSTITUCIÓN CALIFICA ALGO COMO DERECHO, ENTONCES ES UN DERECHO CONSTITUCIONAL}

De la regla $\mathrm{R} 1$ derivamos que todos los derechos establecidos en la Constitución española son derechos fundamentales. Se trata ahora de identificar cuáles son esos derechos constitucionales. Una primera regla consiste en atender a la literalidad de cada precepto constitucional, siguiendo el criterio interpretativo in claris non fit interpretatio. En efecto, si la calificación como derecho en la Constitución es clara, entonces, necesariamente, estamos ante un derecho constitucional ${ }^{12}$.

Podemos decir que: si algo es calificado literalmente como derecho (o como libertad) por la Constitución, entonces es un derecho (o libertad) y está constitucionalizado.

$$
R 2: L x \rightarrow(D x \wedge C x)
$$

Es decir: "Si $x$ es nombrado literalmente como derecho (o como libertad) en la Constitución [Lx], entonces $x$ es un derecho (o libertad)[Dx] y x está constitucionalizado $[C x]^{\prime \prime}$.

Si unimos ambas reglas, R2 y R1, obtenemos la siguiente regla derivada:

$$
\text { RD2.1: }(L x \rightarrow F x) \text {. }
$$

Esto es: "Si $x$ es nombrado literalmente como derecho (o como libertad) en la Constitución [Lx], entonces $x$ es un derecho fundamental [Fx]"13.

12 En este sentido, G. ESCOBAR ROCA, La ordenación constitucional del medio ambiente, Dykinson, Madrid, 1995, p. 56; en "Presupuestos estructurales", cit., pp. 287 y 290; y en “Los derechos fundamentales sociales de prestación (doctrina general)" en G. ESCOBAR ROCA (ed.), Derechos sociales y tutela antidiscriminatoria, Editorial Aranzadi, Pamplona, 2012, pp. 459649, esp., pp. 465-466).

13 En efecto, podemos realizar el siguiente razonamiento, a partir de las reglas R1 y R2, que es una tautología: $\left\{[(D x \wedge C x) \leftrightarrow F x]^{\wedge}\left[L x \rightarrow\left(D x^{\wedge} C x\right)\right]\right\} \rightarrow(L x \rightarrow F x)$. 
En cambio, no podemos, en la regla RD2, usar el argumento a contrario y deducir, erróneamente, que: si algo no es nombrado literalmente como derecho (o como libertad) en la Constitución, entonces ese algo no es un derecho fundamental. Y esto es así porque incurriríamos en la falacia formal de negación del antecedente.

Por tanto, cabe matizar que pueden existir derechos fundamentales no constitucionalizados de manera explícita, sino de manera implícita, esto es, que pueden deducirse de normas o derechos explícitamente constitucionalizados. Así por ejemplo, parte de la doctrina deduce el derecho a un mínimo vital a partir de derechos ya constitucionalizados ${ }^{14}$.

Por su parte, el Tribunal Constitucional ha incorporado derechos fundamentales nuevos, o nuevas facetas de derechos, a partir de derechos preexistentes en la Constitución. Y esto lo ha realizado en virtud de la cláusula de apertura a los tratados internacionales sobre derechos humanos contenida en el artículo 10.2 CE, incorporando la jurisprudencia del Tribunal Europeo de Derecho humanos (TEDH) o del Tribunal de Justicia de la Unión Europea (TJUE). Por lo que se refiere al primero, el TEDH ha reconocido, basándose en el artículo 8 del Convenio (derecho al respeto de la vida privada y familiar y del domicilio) lo que se ha llamado el "derecho frente al ruido" o "derecho al silencio" en el ámbito domiciliario ${ }^{15}$. Esta jurisprudencia ha sido incorporada por el TC, deduciendo tal derecho, o tal faceta nueva, de los derechos a la intimidad y a la inviolabilidad del domicilio ${ }^{16}$.

Asimismo, el TJUE, basándose en los artículos 7 (respeto de la vida privada y familiar) y 8 (derecho a protección de datos de carácter personal) de la Carta de Derechos Fundamentales de la Unión Europea, ha reconocido un específico "derecho al olvido" frente a los motores de búsqueda en Internet (Sentencia de 13 de mayo de 2014, en el asunto C 131/12, asunto Google Spain). Dicho derecho ha sido incorporado a la jurisprudencia constitucional

14 Véase al respecto: E. CARMONA CUENCA, “Los derechos sociales de prestación y el derecho a un mínimo vital”, Nuevas Políticas Públicas, núm. 2, 2006, pp.173-197, esp., pp. 187 ss.; y en "El derecho a un mínimo vital", en G. ESCOBAR ROCA (Editor). Derechos sociales y tutela antidiscriminatoria, Editorial Aranzadi, Pamplona, 2012, pp. 1577-1616, esp. pp. 1585 y ss.

15 Véase entre otras, Sentencias del TEDH: de 9 de diciembre de 1994, caso López Ostra contra Reino de España, de 19 de febrero de 1998, caso Guerra y otros contra Italia, y de 16 de noviembre de 2004, caso Moreno Gómez contra Reino de España.

16 Véase: SSTC 119/2011, de 24 de mayo; 16/2004, de 23 de febrero, y 150/2011, de 29 de septiembre. En esta sentencia puede verse el voto particular del magistrado Manuel Aragón Reyes, disconforme con la recepción de la jurisprudencia del TEDH al respecto. 
en la Sentencia 58/2018, de 4 de junio, de modo que "el derecho al olvido es una vertiente del derecho a la protección de datos personales frente al uso de la informática (art. 18.4 CE), y es también un mecanismo de garantía para la preservación de los derechos a la intimidad y al honor, con los que está íntimamente relacionado, aunque se trate de un derecho autónomo." (FJ 5).

Por lo que se refiere a derechos reconocidos explícitamente en la Constitución, podemos identificar tales derechos en enunciados donde la Constitución usa expresiones como "se reconoce (o "se garantiza") el derecho (o "la libertad")", "todos (o "todas las personas", "los españoles", "los ciudadanos", o cualquier otra categoría de personas) tienen derecho". De acuerdo con la regla derivada RD2, hay derechos fundamentales también fuera del Título I de la Constitución (el cual lleva por nombre "Derechos y deberes fundamentales" $)^{17}$, como, por ejemplo, el derecho a usar el castellano (art. 3.1 CE), o el derecho de los particulares "a ser indemnizados por toda lesión que sufran en cualquiera de sus bienes y derechos, salvo en los casos de fuerza mayor, siempre que la lesión sea consecuencia del funcionamiento de los servicios públicos" (art. 106.2 CE); derecho a una indemnización por los daños causados por error judicial, y por los que sean consecuencia del funcionamiento anormal de la Administración de Justicia (art. 121 CE).

\subsection{Hay derechos fundamentales en el Capítulo III de la CE}

También son auténticos derechos, y, por tanto, derechos fundamentales, los mencionados con tal nombre en el Capítulo III del Título I (arts. 43, 44, $45,47)$, aunque ese Capítulo lleve por título: "De los principios rectores de la política social y económica". No podemos tener en cuenta la denominación del Título I CE, o de cada Capítulo o Sección dentro del mismo, por prestarse a confusión ${ }^{18}$.

Por el contrario, parte de la doctrina se resiste a ver derechos fundamentales fuera del Capítulo II de Título I de la Constitución, y especialmente en

17 Pocos autores admiten la existencia de derechos fundamentales fuera del Título I. Entre los que sí la admiten podemos mencionar a G. ESCOBAR ROCA, en "Tema 21. Los derechos humanos y los derechos fundamentales", cit., p. 433.

18 Véase, en este sentido, entre otros, J. Jiménez Campo, Derechos fundamentales: concepto y garantías, cit., pp. 17 y 18; F. BASTIDA FREIJEDO, “El fundamento de los derechos fundamentales", en Revista Electrónica del Departamento de Derecho de la Universidad de La Rioja, núm. 3, 2005, pp. 41-56, esp. p. 53; J. TAJADURA TEJADA, Los derechos fundamentales y sus garantías, cit., p. 34 . 
el Capítulo III del mismo Título, donde se contiene la mayor parte de los derechos sociales fundamentales ${ }^{19}$. En algunos casos, esto podría deberse a motivos ideológicos ${ }^{20}$.

Se alega, entre otros argumentos, la indeterminación del contenido de muchos derechos del Capítulo III ${ }^{21}$. Sin embargo, todos los derechos fundamentales se caracterizan por el carácter abierto y abstracto de su enunciado normativo $^{22}$. No siempre los derechos sociales son más indeterminados que los derechos civiles y políticos ${ }^{23}$. Es cierto que unos derechos son más indeterminados que otros en la CE, y precisan de un mayor grado de "configuración legal". Pero ésta no es razón suficiente para hacerles perder su naturaleza de derechos fundamentales, porque seguirán teniendo un contenido constitucional, por indeterminado que sea, que el legislador debe respetar.

19 Sobre el concepto de derechos sociales fundamentales, véase: R. ARANGO, El concepto de derechos sociales fundamentales, Legis, Bogotá, 2005; J. RODRÍGUEZ-ARANA MUNOZZ, "Sobre el concepto de los derechos sociales fundamentales", Anuario da Facultade de Dereito da Universidade da Coruña, núm. 19, 2015, pp. 115-140; F. DE FAZIO, "El concepto estricto de los derechos sociales fundamentales", Revista Derecho del Estado, núm. 41, 2018, 173-195. Otros autores exploran la vía indirecta del reconocimiento y protección constitucional de los derechos sociales por su conexión con los derechos "fundamentales". En este sentido, véase: J. I. CUBERO MARCOS, "El reconocimiento de derechos sociales a través de la conexión con derechos fundamentales: hacia una progresiva superación de la doctrina clásica", Revista catalana de dret public, núm. 54, 2017, pp. 118-140; y en "La vis expansiva de los derechos fundamentales y su incidencia en la configuración y exigibilidad de los derechos sociales", Revista española de derecho constitucional, núm. 110, 2017, pp. 105-140. En el mismo sentido, en relación con el derecho a la protección de la salud: P. J. TENORIO SÁNCHEZ, "Naturaleza y contenido del derecho constitucional a la protección de la salud y jurisprudencia de nuestro Tribunal Constitucional relativa al mismo", Revista general de derecho constitucional, núm. 27, 2018, pp. $1-33$.

20 En este sentido, G. PISARELLO, Los derechos sociales y sus garantías. Elementos para una reconstrucción, cit., p. 14. Sobre la negación liberal de los derechos fundamentales procedentes de la aportación socialista, es decir, los derechos económicos, sociales y culturales, véase: G. PECES-BARBA MARTÍNEZ, G., R. ASIS ROIG y M. C. BARRANCO AVILÉS, Lecciones de Derechos Fundamentales, cit., pp. 60 y ss.

21 Por ejemplo, Moreno Trujillo, en relación con el derecho al medio ambiente: E. MORENO TRUJILLO, La protección jurídico-privada del medio ambiente y la responsabilidad de su deterioro, Bosch, Barcelona, 1991, p. 322.

22 M. A. PRESNO LINERA, "Capítulo 2. La estructura de las normas de derechos fundamentales", en AA.VV, Teoría general de los derechos fundamentales en la Constitución española de 1978, Tecnos, Madrid, 2004, pp. 45 y ss., esp. p. 47.

23 En este sentido, véase: V. ABRAMOVICH, Y CH. COURTIS, Los derechos sociales como derechos exigibles, cit., pp. 122 y 123); G. PISARELLO, Los derechos sociales y sus garantías. Elementos para una reconstrucción, cit. pp. 67 y ss.

DERECHOS Y LIBERTADES

ISSN: 1133-0937

Número 44, Época II, enero 2021, pp. 277-315

DOI: https://doi.org/10.20318/dyl.2021.5856 
Al parecer de Prieto Sanchís “esta objeción de la indeterminación ha sido hoy mayoritariamente abandonada en la propia dogmática constitucional" 24 .

Uno de los argumentos más usuales empleados para negar que en el Capítulo III del Título I CE existan derechos fundamentales es el sistema de garantías o nivel de protección de los derechos constitucionales diseñado por la Constitución en al artículo 53. Frente a esto, hay que decir que lo determinante no es el grado de protección del derecho; todos los derechos fundamentales, sea cual sea su ubicación en el texto constitucional, en cuanto normas constitucionales, están protegidos frente al legislador mediante el recurso y la cuestión de inconstitucionalidad, o mediante los procedimientos específicos de reforma constitucional (arts. 167 o 168 CE, según el caso). El menor grado de protección de unos derechos frente a otros no los convierte en derechos constitucionales no fundamentales (expresión que es un contrasentido, de acuerdo con la regla R1). Sostener lo contrario es contradictorio con el carácter de norma suprema de la Constitución.

En virtud del sistema de garantías de los derechos contemplados en la Constitución, para algunos autores sólo son derechos fundamentales los comprendidos en la Sección Primera del Capítulo II de del Título I de la Constitución ${ }^{25}$, pero la mayoría los identifica con los derechos del Capítulo II (arts. 14 a 38$)^{26}$.

24 L. PRIETO SANCHÍs, "Los derechos sociales como derechos fundamentales", ponencia presentada al I Congreso de Filosofía del Derecho para el mundo latino, Alicante, 26-28 de mayo de 2016, p. 14. Disponible en: http://iusfilosofiamundolatino.ua.es/download/Ponencia\%20 Prieto\%20Sanchi\% CC\% 81s.pdf.

25 En este sentido, véase L. MARTÍN RETORTILLO, "Régimen constitucional de los derechos fundamentales", en L. MARTÍN RETORTILLO e I. DE OTTO Y PARDO. Derechos fundamentales y Constitución, Civitas, Madrid, 1988, pp. 75 y ss. Por su parte, Pérez Tremps considera que, en sentido amplio, son derechos fundamentales todos los del Título I (incluidos también los del Capítulo III), pero en sentido estricto sólo lo son los de la Sección Primera del Capítulo II del mismo Título (arts. 15 a 19), por ser éstos los que gozan de mayor nivel de protección constitucional -P. PÉREZ TREMPS, "Lección 6. Los derechos fundamentales", en L. LÓPEZ GUERRA, E. ESPÍN, J. GARCÍA MORILLO, P. PÉREZ TREMPS, M. SATÚSTREGUI. Derecho Constitucional, Vol. I. El ordenamiento constitucional. Derechos y deberes de los ciudadanos, Tirant lo Blanch, Valencia, 2016, pp. 125-142, esp. p. 128.

26 En este sentido, véase: P. CRUZ VILLALÓN, "Formación y evolución de los derechos fundamentales", cit., p. 40, y en "Derechos fundamentales", cit., p. 25; P. CRUZ VILLALÓN y J. PARDO FALCÓN, "Los derechos fundamentales en la Constitución española de 1978", Boletín Mexicano de Derecho Comparado, núm. 97, 2000, pp. 65-154, esp., p. 71; J. R. COSSÍO DÍAZ, Estado social y derechos de prestación, Centro de Estudios Constitucionales, Madrid, 1989, pp. 68 ss.; J. JIMÉNEZ CAMPO, “Artículo 53. Protección de los derechos funda-

ISSN: 1133-0937

DOI: https://doi.org/10.20318/dyl.2021.5856
DERECHOS Y LIBERTADES

Número 44, Época II, enero 2021, pp. 277-315 
Por el contrario, opinamos que todos los derechos constitucionales son fundamentales, y unos derechos no pueden ser más fundamentales que otros $^{27}$, porque todas las normas de la Constitución tienen el mismo rango ${ }^{28}$.

En torno al Capítulo II se ha construido un muro que parece infranqueable. Se llega a una conclusión algo desconcertante, que contradice la regla interpretativa R1: solo hay derechos fundamentales dentro del Capítulo II; extramuros, si hay derechos, son derechos constitucionales, pero no fundamentales.

En vez de poner otro ladrillo en el muro, vamos a intentar romperlo. El muro se ha construido en torno a la interpretación conjunta de los artículos 53.1 y 53.3 CE. Tiene, por así decirlo, dos capas.

3.1.1. Rompiendo la primera capa del muro. El carácter declarativo de las garantías del artículo 53.1 CE

Las garantías del artículo 53.1 CE no son más que una especificación, para los derechos fundamentales, del carácter de norma fundamental de la Constitución. De ahí su carácter meramente declarativo y no constitutivo ${ }^{29}$.

mentales", cit., p. 31, y en Derechos fundamentales: concepto y garantías, cit., p. 27); F. BASTIDA FREIJEDO, "Capítulo 1. Concepto y modelos históricos de los derechos fundamentales". cit, pp. 31 y 32; en "El fundamento de los derechos fundamentales", cit. p. 53 y en "¿Son los derechos sociales derechos fundamentales?", cit., p. 138; L. M. DÍEZ-PICAZO, Sistema de Derechos Fundamentales, cit., pp. 63 y ss.; J. TAJADURA TEJADA, Los derechos fundamentales y sus garantías, cit., p. 37; J. PÉREZ ROYO, Curso de Derecho Constitucional, Marcial Pons, 15. a de, Madrid, 2016, p. 208.

27 En contra, F. BASTIDA FREIJEDO, “Capítulo 1. Concepto y modelos históricos de los derechos fundamentales". cit., 31 y 32; y en "¿Son los derechos sociales derechos fundamentales?", cit., p. 120.

${ }_{28}$ En este sentido, A. IBÁÑEZ MACÍAS, “El medio ambiente como derecho fundamental", Revista de Derecho Urbanístico y medio ambiente, núm. 231, 2007, pp. 141-187, esp., p 143; G. ESCOBAR ROCA, "Presupuestos estructurales", cit., 290. Este autor considera que la dogmática debe "tomarse en serio la fuerza normativa de la Constitución" en materia de derechos fundamentales, y, especialmente, de derechos sociales -G. ESCOBAR ROCA, "El futuro de la dogmática de los derechos". Revista Catalana de Dret Públic, núm. 49, 2014, pp. 61-83, esp., pp. 71 y ss.

${ }_{29}$ Al respecto, A. IBÁÑEZ MACÍAS, "El medio ambiente como derecho fundamental", cit, esp., p. 143. En especial, sobre el carácter declarativo de la cláusula del contenido esencial del artículo 53.1 CE, cláusula que se extiende, por tanto, a todos los derechos constitucionales, véase J. J. SOLOZÁBAL ECHAVARRÍA, "Una revisión de la teoría de los derechos fundamentales", cit., pp. 119-120. Precisamente, durante la tramitación parlamentaria en el Senado del texto constitucional, hubo una enmienda al entonces art. 48.1 CE (actual art. 53.1 CE) pre- 
La vinculación a los poderes públicos es una concreción, para los derechos del Capítulo II, de lo establecido en el artículo 9.1 CE para todas las normas constitucionales ("los ciudadanos y los poderes públicos están sujetos a la Constitución $\left.(. . .)^{\prime \prime}\right)^{30}$, pero a su vez esta última norma es una explicitación del carácter fundamental de la Constitución, obra del poder constituyente $^{31}$. Por tanto, la vinculación a los poderes públicos es una garantía que es aplicable a todos los derechos constitucionales, sea cual sea su ubicación en la Constitución, también a los del Capítulo III de la Constitución (y a los que se hallan fuera del Título I).

Quienes sostienen que solo los derechos del Capítulo II del Título I de la Constitución son derechos fundamentales alegan que estos derechos, en virtud de lo dispuesto en el artículo 53.1 CE, tienen un contenido esencial. De aquí deducen algunos, aplicando el argumento a contrario e incurriendo en la falacia formal de negación del antecedente, que los derechos que se hallan extramuros del Capítulo II carecen de un contenido esencial, y, en consecuencia, son disponibles por el legislador, no son derechos fundamentales. Pero esta interpretación es un tanto apresurada. La Constitución dispone que: “[la] ley [...] en todo caso deberá respetar su contenido esencial [de los derechos del Capítulo II]" (art. 53.1 CE). Dicho de otro modo, "Si se trata de uno de los derechos comprendidos en el Capítulo II, la ley deberá respetar su contenido esencial" ¿Y si se trata de un derecho no comprendido en el Capítulo II? No podemos usar el argumento a contrario para deducir que la ley no está obligada a respetar su contenido esencial. O que estos derechos

sentada por el Grupo Parlamentario Progresistas y Socialistas Independientes (número 38), que propugnaba su supresión total -F. SÁINZ MORENO, Constitución española. Trabajos parlamentarios, Cortes Generales, Madrid, 1980, p. 2685. La enmienda fue defendida por el senador Villar Arregui, p. 3518-. Como ha dicho Gavara de Cara, la aprobación de esta enmienda, que fue rechazada sin ningún tipo de argumentación o réplica, "hubiera evitado las actuales dificultades que supone interpretar de forma coherente los artículos 9 pár. 1 y 53 pár. 1 CE, así como la actual necesidad de identificar el contenido esencial con el contenido constitucionalmente declarado" -J. C. GAVARA DE CARA, Derechos fundamentales y desarrollo legislativo. La garantía del contenido esencial de los derechos fundamentales en la Ley fundamental de Bonn, Centro de Estudios Constitucionales, Madrid, 1994, p. 345.

30 En este sentido, L. MARTÍN RETORTILLO, "Régimen constitucional de los derechos fundamentales", cit. p. 26.

31 En este sentido, véase: I. DE OTTO Y PARDO, Derecho Constitucional. Sistema de Fuentes. Ariel, 2. ${ }^{a}$ ed. Barcelona, 1987, pp. 24 y ss. En cambio, Gavara de Cara, distingue, como conceptos distintos, las expresiones "sujeción" (del artículo 9.1 CE) y “vinculación" (del artículo 53.1 CE), dándole un mayor alcance a la segunda expresión que a la primera -J. C. GAVARA DE CARA, Derechos fundamentales y desarrollo legislativo..., cit., p. 340.

ISSN: 1133-0937

DOI: https://doi.org/10.20318/dyl.2021.5856
DERECHOS Y LIBERTADES

Número 44, Época II, enero 2021, pp. 277-315 
carecen de contenido esencial o constitucional. Esa interpretación iría contra el carácter de norma fundamental de la Constitución.

En efecto, la protección del contenido esencial del derecho es también una especificación del carácter de norma fundamental de la Constitución. Todas las normas tienen un contenido constitucional que el legislador debe respetar, también las normas del Capítulo III CE. Para muchos autores el contenido esencial de un derecho coincide con su contenido constitucionalmente declarado $^{32}$, es decir, contenido esencial y contenido constitucional de un derecho son la misma cosa. Esta parece la conclusión lógica. Desde un punto lógico, la Constitución es un conjunto de enunciados, y cada enunciado contiene términos. Todo término de la Constitución tiene un significado conceptual. Ese significado es su contenido constitucional, que no se define en el propio texto de la Constitución, pero que se presupone o que se habrá de concretar llegado el momento, y que el legislador, en todo caso, debe respetar. El contenido esencial de un derecho no es más su contenido constitucional: es decir, "aquellas facultades o posibilidades de actuación necesarias para que el derecho sea recognoscible como pertinente al tipo descrito y sin las cuales deja de pertenecer a ese tipo y tiene que pasar a quedar comprendido en otro desnaturalizándose, por decirlo así" (STC 11/1981, FJ 8). Su contenido se determina, en su caso, a partir de la dogmática jurídica. No otra cosa quiso decir el TC en la Sentencia 11/1981, al explicar el primer camino para aproximarse a la idea de contenido esencial de un derecho, de cualquier derecho subjetivo:

"Para tratar de aproximarse de algún modo a la idea de 'contenido esencial', que en el art. 53 de la Constitución se refiere a la totalidad de los derechos fundamentales y que puede referirse a cualesquiera derechos subjetivos, sean o

32 Véase en este sentido, entre otros: I. DE OTTO Y PARDO, "La regulación del ejercicio de los derechos fundamentales. La garantía de su contenido esencial en el artículo 53.1 de la Constitución". en L. MARTÍN-RETORTILLO BAQUER e I. DE OTTO Y PARDO. Derechos fundamentales y Constitución, Civitas, Madrid, 1988, pp. 95 y ss., esp., p. 127; A. L. MARTÍNEZPUJALTE, La garantía del contenido esencial de los derechos fundamentales. Centro de Estudios Políticos y Constitucionales, Madrid, 1997, p. 73; J. J. SOLOZÁBAL ECHAVARRÍA, "Los derechos fundamentales en la Constitución española", cit., p. 19; I. VILLAVERDE MENÉNDEZ, "Capítulo 6. Los límites a los derechos fundamentales", en AAVV, Teoría general de los derechos fundamentales en la Constitución española de 1978, Tecnos, Madrid, 2004, pp. 120 y ss., esp., pp. 134 ss.; T. DE DOMINGO, y A. L. MARTÍNEZ-PUJALTE, "La interpretación de la garantía del contenido esencial y la estructura de los derechos fundamentales", en A. L. MARTÍNEZ PUJALTE y T. DE DOMINGO, Los derechos fundamentales en el sistema constitucional. Teoría general e implicaciones prácticas, Editorial Comares, Granada, 2011, pp. 31-55, esp., p. 53; P. CRUZ VILLALÓN, "Derechos fundamentales", cit., p. 25. 
no constitucionales, cabe seguir dos caminos. El primero es tratar de acudir a lo que se suele llamar la naturaleza jurídica o el modo de concebir o de configurar cada derecho. Según esta idea hay que tratar de establecer una relación entre el lenguaje que utilizan las disposiciones normativas y lo que algunos autores han llamado el metalenguaje o ideas generalizadas y convicciones generalmente admitidas entre los juristas, los jueces y, en general, los especialistas en Derecho. (...)Los especialistas en Derecho pueden responder si lo que el legislador ha regulado se ajusta o no a lo que generalmente se entiende por un derecho de tal tipo" 33 .

No parece viable distinguir entre un contenido esencial y un contenido constitucional de un mismo derecho, como si hubiera dos conceptos constitucionales (uno mínimo y otro más amplio o adicional) de un mismo término en la Constitución ${ }^{34}$.

La conclusión es que todos los derechos constitucionales tienen un contenido constitucional o esencial que el legislador debe respetar ${ }^{35}$, de lo contrario no tendrían sentido técnicas de protección de los derechos fundamentales frente al legislador, como los procedimientos de declaración de inconstitucionalidad $^{36}$, que protegen a todas las normas constitucionales, también las del Capítulo III. Negar a los derechos constitucionales no incluidos en el Capítulo II (entre ellos, los del Capítulo III) un contenido (esencial) que

33 STC 11/1981, FJ 8. El resaltado es nuestro. Para Alonso García, este primer camino explicado por el TC para la determinación del contenido esencial es "la máxima expresión" del papel jugado por la dogmática jurídica en la interpretación constitucional (E. ALONSO GARCÍA, La interpretación de la Constitución, Centro de Estudios Constitucionales, Madrid. 1984, pp. 93-94). Sobre las dificultades y problemas que plantea este criterio de determinación del contenido esencial, véase: J. C. GAVARA DE CARA, Derechos fundamentales y desarrollo legislativo, cit., pp. 347 y ss.

34 Además, la distinción entre contenido esencial y contenido constitucional de un derecho plantea problemas en el momento de control de constitucionalidad de las normas. Como ha dicho Gavara de Cara: "Considerar que un derecho fundamental está compuesto de un núcleo y una periferia, de tal modo que la infracción del núcleo produce la inconstitucionalidad de la medida legislativa; tiene como consecuencia excluir del control de constitucionalidad la parte periférica o accidental del derecho, con lo cual el parámetro de control no es el precepto constitucional completo sino una parte del mismo" -J. C. GAVARA DE CARA, Derechos fundamentales y desarrollo legislativo, cit., p. 328.

35 En este sentido, G. PISARELLO, Los derechos sociales y sus garantías. Elementos para una reconstrucción, cit., p. 81.

36 En este sentido, L. PRIETO SANCHÍS, "Los derechos sociales y el principio de igualdad sustancial”, Revista del Centro de Estudios Constitucionales, núm. 22, 1995, pp. 9-56, esp., pp. 45,50 y 51 .

ISSN: 1133-0937

DERECHOS Y LIBERTADES

DOI: https://doi.org/10.20318/dyl.2021.5856

Número 44, Época II, enero 2021, pp. 277-315 
el legislador debe respetar es negarles su condición de derechos constitucionales, algo que no se puede hacer sin incurrir en manifiesta contradicción con la propia Constitución: no pueden existir derechos constitucionales sin contenido, como no pueden existir términos constitucionales sin significado.

Por su parte, el artículo 52.1 de la Carta de Derechos Fundamentales de la Unión Europea protege con la técnica del contenido esencial a todos los derechos de la Carta sin distinción, incluidos los llamados derechos de "solidaridad" 37 . Pues bien, en el caso de nuestra Constitución esta consecuencia es la que se deduce lógicamente del carácter fundamental de todos los derechos constitucionalizados ${ }^{38}$.

Por lo que respecta a las demás garantías del artículo 53.1 CE, es evidente que el recurso de inconstitucionalidad se aplica a todos los derechos constitucionales, sea cual sea su ubicación. Lo mismo podemos decir de la técnica de la reserva de ley. El propio art. 53.3 CE usa la expresión "de acuerdo con lo que dispongan las leyes que los desarrollen", por lo que puede entenderse como una reserva de ley genérica para los "principios" comprendidos en el Capítulo III CE ${ }^{39}$.

3.1.2. Rompiendo la segunda capa del muro. La interpretación de lo dispuesto en el artículo 53.3 CE

En concreto, para negar que los derechos comprendidos en el Capítulo III del Título I sean derechos fundamentales ${ }^{40}$, se alega no sólo que carecen

37 El artículo 52.1 de la Carta dispone que: "Cualquier limitación del ejercicio de los derechos y libertades reconocidos por la presente Carta deberá ser establecida por ley y respetar el contenido esencial de dichos derechos y libertades (...)".

38 En este sentido, Freixes Sanjuan considera que la cláusula del contenido esencial del artículo 53.1 CE es "materialmente irrelevante" -T. FREIXES SANJUAN, "Contenido esencial de los derechos fundamentales", en M. ARAGÓN REYES y C. AGUADO RENEDO (Dir.). Temas básicos de Derecho Constitucional. Tomo III. Derechos fundamentales y su protección, Editorial Aranzadi. 2. ${ }^{\text {e }}$ d., Navarra, 2011, pp. 67-73, esp., p. 72.

39 Véase, al respecto, L. VILLACORTA MANCEBO, Reserva de ley y Constitución, Dykinson, Madrid, 1994, pp. 150-152.

40 Se les llama "derechos aparentes": J. JIMÉNEZ CAMPO, "Artículo 53. Protección de los derechos fundamentales", cit., pp. 123 ss.; en el mismo sentido, Garrido Falla habla de "apariencia de derechos" -F. GARRIDO FALLA, "Garantías de las libertades y derechos fundamentales", en Comentarios a la Constitución, Civitas, $3^{\mathrm{a}}$ ed., Madrid, 2001, 973 y ss., esp. p. 977; Sánchez González dice que el Capítulo III contiene “'derechos' irrealizables” -S. SANCHEZ GONZÁLEZ, "Lección 1. Los derechos fundamentales en la Constitución española de 1978", en S. SÁNCHEZ GONZÁLEZ (coord.), Dogmática y práctica de los derechos funda- 
de contenido esencial (lo cual ha sido contestado en el epígrafe anterior), sino que no se pueden invocar directamente ante los tribunales, en virtud de lo dispuesto en el artículo 53.3 CE: los principios reconocidos en el Capítulo III (principios rectores de la política social y económica) "sólo podrán ser alegados ante la Jurisdicción ordinaria de acuerdo con lo que dispongan las leyes que los desarrollen". Nótese que aquí no estamos ante un término que deba ser interpretado literalmente, como el término "derecho" o "libertad" contenido expresamente en la Constitución en relación con la regla interpretativa R2. No se trata de interpretar un solo término, sino todo un enunciado de significado ambiguo ${ }^{41}$. Una posible interpretación de este enunciado puede ser formulada del siguiente modo: "Si y solo si ("sólo" dice el texto de la Constitución) hay leyes que los desarrollen, y se alegan de acuerdo con tales leyes, entonces los principios reconocidos en el Capítulo III podrán ser alegados ante la Jurisdicción ordinaria". De aquí se ha querido deducir que tales principios no se pueden invocar directamente ante los tribunales (no tienen eficacia directa), sino de acuerdo con las leyes los desarrollen (eficacia indirecta), luego -se concluye- no son derechos fundamentales ${ }^{42}$.

Ahora bien, esta interpretación del artículo 53.3 CE entra en contradicción con la calificación literal como "derecho" dada por la propia Constitución en algunos de los preceptos del Capítulo III: “derecho a la pro-

mentales, Tirant lo Blanch, Valencia, 2006, p. 22; Pérez Tremps niega que estemos en presencia de derechos subjetivos, en virtud de la interpretación que da al artículo 53.3 CE -P. PÉREZ TREMPS, "Lección 6. Los derechos fundamentales", cit., p. 133; J. Pérez Royo los califica como "los no derechos fundamentales" -J. PÉREZ ROYO, Curso de Derecho Constitucional, cit., p. 209.

41 Sobre el carácter impreciso o incluso desafortunado de este precepto, véase: J. L. SERRANO MORENO, "Algunas hipótesis sobre los principios rectores de la política social y económica", Revista de Estudios Políticos, núm. 56, 1987, pp. 95-120, esp., p. 117.

42 Véase, en este sentido, entre otros: F. GARRIDO FALLA, “El artículo 53 de la Constitución", Revista Española de Derecho Administrativo, núm. 21, 1979, pp. 173-188, esp., pp. 179-180; T. R. FERNÁNDEZ, "Los derechos fundamentales y la acción de los poderes públicos". Revista de Derecho Político, núm. 15, 1982, pp. 21-34, esp., p. 29; J. JIMÉNEZ CAMPO, Derechos fundamentales: concepto y garantías, cit., pp. 123 y 124; G. PECES-BARBA MARTÍNEZ, R. ASIS ROIG y M. C. BARRANCO AVILÉS, Lecciones de Derechos Fundamentales, cit., p. 283; L. M. DÍEZ-PICAZO, Sistema de Derechos Fundamentales, cit., pp. 62 ss.; F. BASTIDA FREIJEDO, "El fundamento de los derechos fundamentales", cit., p. 46; y en "¿Son los derechos sociales derechos fundamentales?”, 2007: 138; A. OEHLING DE LOS REYES, “El artículo 53 de la constitución española de 1978: esquema de la evolución y del estado de situación de sus instrumentos de garantía de los derechos fundamentales (1978-2017)". UNED. Revista de Derecho Político, núm. 100, 2017, pp. 1099-1136, esp., pp. 1133 y ss. 
tección de la salud" (art. 43.1 CE), "derecho a disfrutar de un medio ambiente adecuado para el desarrollo de la persona (art. 45.1), "derecho a disfrutar de una vivienda digna y adecuada" (art. 47); "derecho" a la cultura (art. 44.1 $\mathrm{CE}$ ). No puede la Constitución, sin entrar en contradicción consigo misma, proclamar literalmente derechos constitucionales y, al mismo tiempo, negarles su condición de derechos con el subterfugio de prohibirles su alegación directa ante los tribunales, sin previa ley de desarrollo ${ }^{43}$.

Vamos a intentar armonizar la naturaleza de derechos (fundamentales) de los así proclamados literalmente en el Capítulo III con lo dispuesto en el art. 53.3. Para ello, vamos a abrir una brecha en esta segunda capa del muro. Aunque todos estuviésemos de acuerdo en que el verdadero significado del enunciado transcrito es el que le hemos dado más arriba, todavía podríamos discrepar en cuanto a su ámbito de aplicación. La mayoría de la doctrina ha presupuesto que el enunciado del art. 53.3 CE se refiere a todas las normas del Capítulo III, sin distinción, pues este Capítulo lleva por título “De los principios rectores de la política social y económica". Ahora bien, no podemos quedarnos en el título del Capítulo, sino que tenemos que estudiar la verdadera naturaleza de cada una de las normas del Capítulo III.

El hecho de que el art. 53.3 CE se refiera a "los principios (rectores) reconocidos en el Capítulo III" no significa que todas las normas del Capítulo III contengan principios rectores, de mismo modo que no todas las normas del Capítulo II, a pesar de su título, contienen derechos ${ }^{44}$. Sostenemos que el art. 53.3 CE no se refiere a todas las normas del Capítulo III, sino solo a las que contienen "principios (rectores)", no a las normas que reconocen literalmente derechos, como los ya mencionados artículos 43.1, 44.1, 45.1, y $47 \mathrm{CE}^{45}$.

43 Al respecto, Revenga Sánchez habla de "las incongruentes tomas de posición de una Constitución que parece diseñada para reconocer derechos sociales y al tiempo desactivarlos" -M. REVENGA SÁNCHEZ, "Los Derechos Sociales (Instrumentos de Garantía en la Constitución Española)". Asamblea: Revista Parlamentaria de La Asamblea de Madrid, núm. 21, 2009, pp. 97-106, esp. p. 98.

44 Sobre esto, J. JIMÉNEZ CAMPO, “Artículo 53. Protección de los derechos fundamentales", pp. 31 y ss.

45 En este sentido, referido al derecho a la protección del medio ambiente, G. ESCOBAR ROCA, La ordenación constitucional del medio ambiente, cit., p. 73; D. LOPERENA ROTA, El derecho al medio ambiente adecuado. Civitas, Madrid, 1996, p. 50; A. IBÁÑEZ MACÍAS, “El medio ambiente como derecho fundamental", cit., pp. 160-161. Con carácter más general, extendiendo esta interpretación a todos los derechos del Capítulo III, véase G. ESCOBAR ROCA, "Presupuestos estructurales", cit., p. 296. Asimismo, considera que hay derechos en el capítulo III: J. L. CASCAJO CASTRO, “Derechos sociales”, Cuadernos de derecho público, núm. 
Hay que distinguir entre normas del Capítulo III que contienen "principios rectores", a las que se aplica la limitación art. 53.3 CE, y las que contienen (literalmente) derechos, a las que no se aplica tal limitación en cuanto a la posibilidad de ser alegados directamente ante la jurisdicción ordinaria.

Respecto de las normas del Capítulo III que contienen "principios rectores", el artículo 53.3 CE (al igual que hemos constatado respecto del art. 53.1 $\mathrm{CE})$ debe de tener un carácter meramente declarativo. Es decir, hay algo en la naturaleza de tales principios rectores que impide que puedan ser alegados directamente por los particulares ante los tribunales ordinarios como "derechos" o como "intereses legítimos" (art. 24), sin una previa ley de desarrollo. En efecto, los principios rectores son mandatos a los poderes públicos ${ }^{46}$ (es-

37, 2009, pp. 11-35, esp., pp. 17-18. Por el contrario, Satrústegui considera que los preceptos del Capítulo III son de contenido heterogéneo, e incluso hay normas que contienen derechos como el de la salud, pero aplica a estos derechos lo dispuesto en el artículo $53.3 \mathrm{CE}$, y por tanto concluye que "estos preceptos constitucionales [los del Capítulo III que contienen derechos] no crean derechos públicos subjetivos, susceptibles de obtener inmediatamente una tutela judicial, sino más bien expectativas de derechos o derechos incompletos que deben ser concretados por el legislador" -M. SATRÚSTEGUI, "Lección 18. Derechos de ámbito económico y social", EN L. LÓPEZ GUERRA, E. ESPÍN. J. GARCÍA MORILLO, P. PÉREZ TREMPS, M. SATÚSTREGUI. Derecho Constitucional Vol I. El ordenamiento constitucional. Derechos y deberes de los ciudadanos, Tirant lo Blanch. Valencia, 2016, pp. 377-402, esp., p. 390-. Por su parte, Álvarez-Ossorio distingue entre los derechos sociales del Capítulo II (igualdad y educación), que son auténticos derechos fundamentales, y los derechos sociales del capítulo III (salud y vivienda) que son meros principios rectores, a los que se aplica el artículo 53.3 CE. En consecuencia, considera, respeto de los "derechos sociales integrados en el ámbito de los principios" que "deben esperar a lo que sobre los mismos decida el legislador (es entonces y sólo entonces cuando podrán ser esgrimidos ante los tribunales de justicia, art. 53.3 CE)" -F. ÁLVAREZ-OSSORIO MICHEO, “Capítulo XXIIII. Derechos fundamentales. Igualdad y educación", en M. Agudo Zamora y otros. Manual de Derecho Constitucional, Tecnos, $7^{\mathrm{a}}$ ed., Madrid, 2016, pp. 608 a 627, esp., p. 610-. Finalmente Porras Nadales distingue, dentro del Capítulo III, entre principios y derechos (a la protección de la salud, de acceso a la cultura, de medio ambiente y de vivienda), pero aplica a éstos últimos el art. $53.3 \mathrm{CE}$, como si se trataran de principios rectores -A. PORRAS NADALES, "Los principios rectores de la política social y económica", en M. AGUDO ZAMORA y otros, Manual de Derecho Constitucional, Tecnos, $7^{\mathrm{a}}$ ed., Madrid, 2016, pp. 628 a 654, esp. p. 632-. Sin embargo, en una obra más temprana este autor mantiene una posición interpretativa del art. 53.3 CE en el sentido de que "tales derechos no deben considerarse incluidos en la norma restrictiva del art. 53.3 de la Constitución, que sólo habla de los principios reconocidos en el Capítulo Tercero" -A. PORRAS NADALES, "Garantías de los derechos", en J.J. GONZÁLEZ ENCINAR, (dir.). Diccionario del sistema político español, Akal, Madrid, 1984, p. 375-. Las cursivas son del original.

46 Escobar Roca considera que las normas el Capítulo III no contienen principios constitucionales propiamente dichos, "pero sí derechos, mandatos a los poderes públicos y nor-

ISSN: 1133-0937

DOI: https://doi.org/10.20318/dyl.2021.5856
DERECHOS Y LIBERTADES

Número 44, Época II, enero 2021, pp. 277-315 
tos son principalmente sus destinatarios) en relación con la política social y económica. Solo cuando tales principios son desarrollados por el legislador, dan lugar a derechos alegables ante los tribunales.

No sucede lo mismo con las normas del Capítulo III que reconocen directa y literalmente derechos. Estos derechos nacen directamente de la Constitución. Impedir que los ciudadanos puedan alegar estos derechos ante los tribunales, en ausencia de ley de desarrollo, o incluso contra la ley de desarrollo (formulando alegaciones para que el juez plantee una cuestión de inconstitucionalidad contra la ley que los regula), puede entenderse que vulnera el derecho de todas las personas a obtener la tutela de los jueces y tribunales en el ejercicio de sus derechos e intereses legítimos (art. 24 CE), en este caso, de sus derechos constitucionales.

Tenemos que distinguir, a lo largo del texto constitucional, y en especial en el Capítulo III, entre derechos constitucionales y principios rectores, esto es, mandatos a los poderes públicos para hacer efectivos tales derechos. Los primeros, y a pesar de las dificultades de su justiciabilidad cuando se tratan de derechos sociales de prestación, son invocables directamente ante la jurisdicción ordinaria. Los segundos, al menos los mandatos a los poderes públicos a que se refiere el art. 53.3 CE, precisan una ley de desarrollo para su alegación por los particulares ante la jurisdicción ordinaria.

En ocasiones, los mandatos a los poderes públicos pretenden hacer efectivos, o garantizar, derechos fundamentales preexistentes, reconocidos por la Constitución. En estos casos, podemos entender que tales mandatos forman parte de las garantías del derecho ${ }^{47}$.

Pongamos un ejemplo. El artículo 35 reconoce el derecho al trabajo. Puesto que la norma se contiene en el Capítulo II, estamos, claramente, sea cual sea la interpretación que demos al art. 53.3 CE, ante un derecho fundamental y no ante un "principio rector". Sin embargo, en relación con tal derecho fundamental, el art. 40.1 contiene un principio rector del siguiente tenor: "[Los poderes públicos] de manera especial realizarán una política orientada al pleno empleo". Esos poderes públicos son los poderes legislati-

mas de organización y procedimiento" -G. ESCOBAR ROCA, "Presupuestos estructurales", cit., pp. 291-292.

47 En este sentido, ESCOBAR ROCA considera que: "Cuando los mandatos acompañan a los derechos (p. ej., arts. 27.5 y 8, 43.2, 44.1, 46 ó 47) sirven para ampliar su contenido meramente subjetivo y para reforzar sus garantías" (G. ESCOBAR ROCA, "Presupuestos estructurales", cit., p. 306). 
vos y ejecutivos de los entes territoriales, de acuerdo con sus competencias y atribuciones, no el poder judicial, cuya función no es política, sino jurisdiccional (art. 117 CE, apartados 3 y 4). A los poderes legislativos y ejecutivos van destinados los principios rectores de la "política" social y económica. Y en esto no pueden ser sustituidos o suplantados por los jueces, en ausencia de ley de desarrollo de tales principios rectores. Esto es lo que parece que viene a significar el artículo $53.3^{48}$. Si no hay ley de desarrollo, el juez no puede actuar contra la inacción del poder ejecutivo. Tampoco puede plantear una cuestión de inconstitucionalidad contra una omisión legislativa total (el artículo $163 \mathrm{CE}$ requiere que se plantee contra una "norma con rango de ley"). La discusión al respecto parece un tanto bizantina, transcurridos más de cuarenta años desde la entrada en vigor de la Constitución, y habiendo sido desarrollados, en mayor o menor medida, prácticamente todos los mandatos del Capítulo III. En cambio, si hay ley de desarrollo (por ejemplo, una ley de empleo), en teoría podría plantearse una cuestión de inconstitucionalidad contra la misma por vulneración del derecho al trabajo (art. 35) o del mandato del art. $40.1 \mathrm{CE}$, que se refiere a la dimensión colectiva del derecho al trabajo (STC 22/1981, de 2 de julio, FJ 8).

En el anterior ejemplo, hemos tomado un derecho del Capítulo II (art. $35 \mathrm{CE}$ ) y un mandato a los poderes públicos contenido en el Capítulo III (art. 40. 1 CE), en garantía de tal derecho. Pues bien, hay que tener en cuenta que, en ocasiones, los mandatos a los poderes públicos del Capítulo III pretenden garantizar, o hacer efectivos, derechos reconocidos literalmente en el mismo Capítulo III. En efecto, el artículo 43 CE reconoce literalmente el derecho a la protección de la salud en su apartado primero. $Y$ los apartados segundo y tercero del mismo artículo contienen mandatos a los poderes públicos para hacer efectivo tal derecho. El artículo $44.1 \mathrm{CE}$, al tiempo que reconoce el derecho a la cultura, establece un mandato a los poderes públicos para que promuevan y tutelen el acceso a la misma. El artículo $45 \mathrm{CE}$ reconoce en su apartado primero "el derecho a disfrutar de un medio ambiente adecuado para el desarrollo de la persona". Y en los apartados 2 y 3 establece mandatos a los poderes públicos para hacerlo efectivo. Por último, el art. 47 CE estable-

48 En este sentido, Laporta ha dicho que en el artículo $53 \mathrm{CE}$, "se opta claramente por el principio democrático" -F. J. LAPORTA, "Los derechos sociales y su protección jurídica: introducción al problema", en J. BETEGÓN, J. R. DE PÁRAMO, F. J. LAPORTA y L. PRIETO SANCHÍS (coords.), Constitución y derechos fundamentales, Ministerio de la Presidencia, Secretaría General Técnica, Centro de Estudios Políticos y Constitucionales, Madrid, 2004, pp. 297-325, esp. p 322. 
ce en su primer enunciado el "derecho a disfrutar de una vivienda digna y adecuada". Y el enunciado inmediatamente siguiente establece un principio rector o mandato a los poderes públicos "para hacer efectivo este derecho".

Sucede, sin embargo, que prácticamente todos los derechos del Capítulo III (salvo, algunas excepciones, como la igualdad de los hijos ante la ley con independencia de su filiación, art. 39.2 CE) son derechos sociales de prestación, y necesariamente, por ello mismo, derechos de configuración legal. Es decir, para que estos derechos sean efectivos, su contenido ha de ser necesariamente concretado por el legislador ${ }^{49}$. Como hemos visto más arriba, al comentar la regla $\mathrm{R} 1$, esto sucede con todos los derechos de configuración legal, incluso con derechos que se hallan en la Sección I del Capítulo Segundo del Título I, como los derechos a participar en los asuntos públicos (art. 23 CE), a la tutela judicial efectiva (art. 24 CE), y a la educación (art. 27 CE), que tienen el máximo nivel de protección constitucional (art. 53.2 CE). Su invocación directa ante la "jurisdicción orninaria", incluso por el procedimiento preferente y sumario del art. 53.2 CE, en el supuesto de omisión legislativa total, no sería efectiva. El juez no podría plantear la cuestión de inconstitucionalidad contra la omisión de ley reguladora, pues este procedimiento de declaración de inconstitucionalidad tiene por objeto "una norma con rango de ley", no una omisión legislativa total. Una vez regulado el derecho por ley, ya cabría plantear una cuestión de inconstitucionalidad contra dicha ley. Esto mismo sucede, como no pude ser de otro modo, con los derechos sociales de prestación del Capítulo III CE.

Como se observa, la efectividad de estos derechos de configuración legal, sea cual sea su ubicación en los diferentes capítulos y secciones del Título I, es muy similar a la de los mandatos a los poderes públicos del Capítulo III. Éstos no pueden ser alegados ante la jurisdicción ordinaria en defecto total de ley de desarrollo (art. 53.3 CE); aquéllos, aunque puedan ser alegados directamente ante los tribunales (no se les aplica el límite del artículo 53.3), carecen de efectividad ante los mismos en caso de omisión legislativa total. Pero tanto en el caso de los mandatos a los poderes públicos del Capítulo III ${ }^{50}$, como en de los derechos de configuración legal, cabe plantear una cuestión de inconstitucionalidad frente a la ley que los regule. Lo cual significa

49 En este sentido, A. IBÁÑEZ MACÍAS, “El medio ambiente como derecho fundamental", cit., p. 160.

50 En este sentido, véase: L. PRIETO SANCHÍS, “Los derechos sociales y el principio de igualdad sustancial", cit., pp. 45, 50 y 51 . 
que, en ambos casos, tanto el contenido constitucional del derecho que la ley debe configurar, como el mandato constitucional (o principio rector) que la ley debe desarrollar (art. 53.3 CE), preexisten al legislador ${ }^{51}$.

A pesar de lo que acabamos de decir, la distinción, dentro del Capítulo III, entre derechos constitucionales (por tanto, fundamentales, aunque sean muchos de ellos de configuración legal), y mandatos a los poderes públicos para hacerlos efectivos, es de gran relevancia a efectos teóricos y sistemáticos:

- Los derechos tienen un contenido constitucional (que hemos identificado con su contenido esencial al interpretar las garantías del art. 53.1 CE), y que el legislador debe respetar, en todo caso, al concretarlo. Son de aplicación aquí los dos criterios ofrecidos por el TC para la determinación del contenido esencial de un derecho (STC 11/1981, FJ 8.).

- Los derechos del Capítulo III, aunque sean muchos de ellos de configuración legal, tienen una titularidad. Esa titularidad viene determinada por los que disponga la propia Constitución, interpretada desde los tratados internacionales sobre derechos humanos ratificados por España (art. 10.2 CE), no queda al albur de lo que disponga la ley de desarrollo. En cambio, los mandatos a los poderes públicos tienen como destinatarios a estos últimos, sujetos pasivos (y no activos), de derechos reconocidos por la Constitución a los ciudadanos o a las personas, según el caso.

Además, la consideración de los derechos del Capítulo III como auténticos derechos y no como meros mandatos a los poderes públicos, tiene importantes implicaciones sistemáticas en el conjunto del texto constitucional. Podemos señalar, al menos, las siguientes:

- Implicaciones en la interpretación de los derechos fundamentales. A la interpretación de los derechos del Capítulo III se le debe aplicar el art. 10.2 CE: “Las normas relativas a los derechos fundamentales

51 En este sentido, sin distinguir entre principios rectores y derechos: G. PISARELLO, Los derechos sociales y sus garantías. Elementos para una reconstrucción, cit., pp. 83-85; L. PRIETO SANCHÍS, "Los derechos sociales y el principio de igualdad sustancial", cit. p. 45, y en El constitucionalismo de los derechos. Ensayos de filosofía jurídica, Editorial Trotta, Madrid, 2013, esp. p. 15. Sin embargo, para este autor el derecho subjetivo no nace hasta que el legislador regula la prestación concreta en que consiste el derecho (L. PRIETO SANCHÍS, "Los derechos sociales como derechos fundamentales", cit., p. 17), lo cual es diferente de lo que aquí venimos sosteniendo. 
y a las libertades que la Constitución reconoce se interpretarán de conformidad con la Declaración Universal de Derechos Humanos y los tratados y acuerdos internacionales sobre las mismas materias ratificados por España". Este artículo ha sido aplicado por la doctrina y por la jurisprudencia constitucional a derechos del Capítulo III (como el derecho a la protección de la salud, STC 139/2016, FJ. 10), lo cual no sería posible si no estuviéramos ante auténticos derechos fundamentales, y no ante meros principios rectores o mandatos a los poderes públicos.

- Implicaciones en relación con los derechos de los extranjeros. A los derechos del Capítulo III, se les aplica el art 13.1 CE, según el cual "los extranjeros gozarán en España de las libertades públicas [derechos según la jurisprudencia constitucional, STC 107/1984, FJ. 3] que garantiza el presente Título en los términos que establezcan los tratados y la ley". El TC no ha dudado en aplicar este precepto, llegado el caso, por ejemplo, al derecho de la protección de la salud del art. 43.1 CE (Véase, entre otras, STC 139/2016, FFJJ 8 y 10).

- Implicaciones en relación con la garantía institucional del Defensor del Pueblo que, según el art. 54 CE, se extiende a todos los derechos del Título I, sin distinción (también a los del Capítulo III), y así es, en efecto, en la práctica de esta institución.

- Implicaciones en el sistema de fuentes del derecho. Sin necesidad de realizar un análisis más exhaustivo del sistema de fuentes, basta señalar que a los derechos del Capítulo III se les debe aplicar el artículo 86.1 CE: los Decretos-leyes "no podrán afectar (...) a los derechos, deberes y libertades de los ciudadanos regulados en el Título I". Por el contrario, es criticable, por incoherente y regresiva, la Sentencia 139/2016, de 15 de agosto, en la que el Tribunal Constitucional ha llegado a declarar, en relación con el derecho a la protección de la salud que: "Atendiendo, por tanto, a su ubicación sistemática, el art. $43 \mathrm{CE}$ se configura como un principio rector, razón por la que carece de contenido constitucionalmente esencial, que pueda ser afectado por la legislación de urgencia. // Debe partirse, en consecuencia, de que el art. 43 no ostenta las características de derecho cuya regulación por decreto-ley impide el art. 86.1 CE" (FJ 6, letra a). Sin embargo, en la misma Sentencia se califica el derecho a la protección de la salud como "derecho de configuración legal", llegando a examinarse su titularidad en relación con los extranjeros (FFJJ 8 y 


\section{0), lo cual se contradice con la primera consideración como mero principio rector a efectos de su afectación por Decreto ley ${ }^{52}$.}

Este cambio de línea jurisprudencial del TC en la Sentencia 139/2016 ha sido especialmente criticado, en un voto particular, por el magistrado Fernando Valdés Dal-Ré por su carácter inmotivado y regresivo para los derechos sociales ${ }^{53}$.

- También se debe aplicar a los derechos del Capítulo III, dentro del sistema de fuentes, lo dispuesto en el artículo 94.1, letra c), que exige previa autorización por las Cortes Generales para la conclusión de

52 Para un comentario crítico de esta Sentencia, en especial en relación con el derecho a la asistencia sanitaria de los inmigrantes en situación irregular, véase: L. E. DELGADO DEL RINCÓN, "El derecho a la protección de la salud de los inmigrantes en situación administrativa irregular: reflexiones críticas sobre la reciente jurisprudencia constitucional acerca de las restricciones introducidas por el Decreto Ley 16/2012, de 20 de abril", Revista Española de Derecho Constitucional, núm. 112, 2018, pp. 287-314. Por el contrario, Rey Martínez considera que el derecho a la protección de la salud es un mero principio rector, y propone una reforma constitucional para convertirlo en un derecho constitucional de configuración legal -F. REY MARTÍNEZ, "Protección de la salud, atención primaria y derechos fundamentales", Teoría y realidad constitucional, núm. 41, 2018, pp. 281-296, esp. p. 295-. Sobre el retroceso de la reciente jurisprudencia del TC relativa a la incidencia de los decretos leyes en los derechos sociales, véase: M. HERNÁNDEZ RAMOS, “La respuesta del Tribunal Constitucional a los DecretosLeyes en materia de derechos sociales. El criticable retroceso de la jurisprudencia constitucional", Revista Vasca de Administración Pública, núm. 109-II, 2017, pp. 119-143.

53 En concreto, en el voto particular de la Sentencia 139/2016, el magistrado Valdés Dal-Ré dirá: “(...) es obligado dejar constancia de que, hasta la actualidad, ninguna resolución de este Tribunal ha procedido a excluir del ámbito de aplicación de la cláusula de "no afectación" los principios rectores enunciados en el capítulo III, título I, CE; o, por expresar la misma idea desde la otra vertiente, este Tribunal, en su ya dilatada trayectoria jurisdiccional, no ha limitado la operatividad de dicha cláusula a los derechos, deberes y libertades consagrados -parece ser ese el alcance de la Sentencia de mi discrepancia- en el capítulo II, de ese mismo título I./ /Una modificación de tanta intensidad como la ahora defendida en la presente resolución hubiera demandado, de seguro, un relevante desarrollo argumentativo. Y no solo ni tanto por llevar asociada un cambio o, al menos, una reinterpretación en la doctrina hasta ahora mantenida por este Tribunal. Esa exigencia viene fundada, además y señaladamente, por los efectos restrictivos que ese cambio o reinterpretación producen en la protección de los derechos y principios constitucionales o, lo que es igual, por los efectos expansivos de un poder normativo de carácter excepcional. La preferencia expresada por la Sentencia a favor de la eliminación de trabas al ejercicio de este poder, pretiriendo la opción enderezada a salvaguardar las posiciones jurídicas de los ciudadanos, se distancia, sin justificación alguna, de la tutela y preservación de la cláusula social (art. 1.1 CE), debilitando la calidad democrática de nuestro sistema de monarquía parlamentaria."

ISSN: 1133-0937

DOI: https://doi.org/10.20318/dyl.2021.5856
DERECHOS Y LIBERTADES

Número 44, Época II, enero 2021, pp. 277-315 
tratados internacionales que afecten a "los derechos y deberes fundamentales establecidos en el Título I".

- Implicaciones en el sistema de distribución de competencias entre el Estado y las Comunidades Autónomas. Se debe aplicar a los derechos del Capítulo III, a reserva de título competencial más específico, lo dispuesto en el artículo 1491.1.1 CE, que reconoce competencia exclusiva al Estado sobre la regulación de las condiciones básicas que garanticen la igualdad de todos los españoles en el ejercicio de los derechos y en el cumplimiento de los deberes constitucionales" 54 .

Hemos, pues, abierto una importante brecha en la segunda capa del muro que supone el art. 53.3 CE, distinguiendo entre derechos expresamente reconocidos en el Capítulo III, a los que no se les aplica lo dispuesto en el art. $53.3 \mathrm{CE}$, y principios rectores en sentido estricto o mandatos a los poderes públicos, a los que sí se les aplicaría.

Podemos ampliar la brecha, de modo que algunas normas del Capítulo III contienen mandatos explícitos a los poderes públicos para proteger y hacer efectivos derechos implícitos en la propia norma. Por ejemplo, el art. 50 CE dispone que: "Los poderes públicos garantizarán, mediante pensiones adecuadas y periódicamente actualizadas, la suficiencia económica a los ciudadanos durante la tercera edad". Aquí el derecho constitucional implícito reconocido a los ciudadanos es el derecho a la suficiencia económica durante la tercera edad, y el mandato explícito a los poderes públicos mediante el que se pretende proteger y hacer efectivo el derecho, es que éstos la garanticen "mediante pensiones adecuadas y periódicamente actualizadas".

En definitiva, en ocasiones (habría que verlo caso por caso), los mandatos a los poderes públicos no son más que garantías de derechos previamente reconocidos por la Constitución, ya sea de manera explícita (literalmente), ya sea de manera implícita.

De este modo, podemos seguir ampliando la brecha en el muro que contiene los derechos fundamentales en el Capítulo II del Título I CE, no solo mediante la aplicación de la regla R2, sino mediante otras reglas interpretativas, como son las reglas R3 y R4, que veremos a continuación.

54 La mayoría de la doctrina considera que el artículo 149.1.1 CE es aplicable a los derechos del Capítulo III. En cambio, la STC 247/2007 (FJ 13) restringe la aplicación de dicho precepto a los derechos del Capítulo II. Al respecto véase: J. M. CASTELLÀ ANDREU, “La Constitución territorial", en G. ESCOBAR ROCA (ed.), Derechos sociales y tutela antidiscriminatoria, Editorial Aranzadi, Pamplona, 2012, pp. 376-402, esp. p. 396, y los autores allí citados. 


\section{REGLA TRES: LA ATRIBUCIÓN DE UN PODER A LOS PARTICU- LARES POR LA CONSTITUCIÓN IMPLICA EL RECONOCIMIENTO DE UN DERECHO}

Los derechos fundamentales son derechos subjetivos constitucionalizados. Aunque el concepto de derecho subjetivo es polémico, y puede revestir diversas formas (una pretensión, un privilegio, una potestad o una inmunidad, en la clasificación de Hohfeld ${ }^{55}$; o un "derecho a algo", una libertad o una competencia, en la de Alexy ${ }^{56}$ ) podemos decir que lo relevante es que una norma (en nuestro caso, de rango constitucional) confiere a una persona un poder-hacer o un poder-no-hacer algo (o un conjunto de poderes). Se diferencia de un no-poder-hacer (una prohibición de hacer) y de un no-poder-no-hacer (una obligación de hacer). A ese poder-hacer o poder-no-hacer algo se le llama, en lógica jurídica, permisión. Se le llama permisión fuerte (o positiva) cuando es la norma la que lo atribuye expresamente, y permisión débil (o negativa), cuando la norma no lo atribuye expresamente, sino que se infiere de la ausencia de una prohibición expresa de hacer algo $^{57}$. La permisión débil se expresa en el dicho: “Lo que no está jurídicamente prohibido, está jurídicamente permitido" 58 , que encierra una tautología ${ }^{59}$.

Por su parte, una facultad consiste en un poder-hacer $\mathrm{y}$, al mismo tiempo, en un poder-no-hacer algo (expresarse y no expresarse, reunirse y no reunirse, asociarse y no asociarse) ${ }^{60}$. Es lo que solemos llamar libertad (de expresión, de reunión, de asociación, etc) ${ }^{61}$.

55 W. HOHFELD, Conceptos jurídicos fundamentales, Traducción de G. Carrió, Fontamara, México DF., 1991.

56 R. ALEXY, Teoría de los derechos fundamentales, cit. pp. 186 y ss.

57 Para la distinción entre permisión fuerte y débil, véase entre otros: C. E. ALCHOURRÓN, “Lógica de las normas y lógica de las proposiciones normativas”, en C. E. ALCHOURRON y E. BULYGIN. Análisis lógico y Derecho, Centro de Estudios Constitucionales, Madrid, 1991, pp. 25-49, esp., pp. 31-32.

58 H. KELSEN, Teoría pura del Derecho, traducción de R. J. Vernengo, UNAM, México, 1982, p. 252.

59 Véase al respecto: C. E. ALCHOURRÓN y E. BULYGIN, Introducción a la metodología de las ciencias jurídicas y sociales, Editorial Astrea, Buenos Aires, 1987, pp. 172-178.

60 En lógica jurídica, se dice que algo es facultativo cuando está permitido hacerlo y no hacerlo. Es decir, no está prohibido hacerlo ni no hacerlo. La definición de facultativo es: F= $\mathrm{Pa}^{\wedge} \mathrm{P} \sim$ a. Véase: C. E. ALCHOURRÓN, "Lógica de las normas y lógica de las proposiciones normativas", cit., p. 27.

61 Así es definida la libertad jurídica por Alexy, en relación, por ejemplo, con la libertad de expresión: “Le está (jurídicamente) permitido a a expresar su opinión y a a le está (jurídica- 
Podemos decir entonces que: si algo es un poder (una permisión o una facultad) [Px] atribuido por una norma a los particulares, entonces ese algo es un derecho [Dx].

$$
R 3: P x \rightarrow D x .
$$

En efecto, en la clasificación general de las normas, las que atribuyen derechos pueden incluirse dentro de las normas permisivas ${ }^{62}$.

Si añadimos a R3 la regla $\mathrm{R} 1$, entonces deducimos la siguiente regla derivada.

$$
\text { RD3.1: }\left(P x^{\wedge} \mathrm{C} x\right) \rightarrow F x \text {. }
$$

Es decir, si ' $x$ ' es un poder (permisión o facultad) atribuido a los particulares [Px] $y$ ' $x$ ' está constitucionalizado [CX], entonces ' $x$ ' es un derecho fundamental [Fx].

Como se aprecia en esta regla, sólo se tienen en cuenta las permisiones fuertes, esto es, las previstas en la Constitución. No se tienen en cuenta las permisiones débiles o negativas, definidas como ausencias de prohibiciones expresas, pues deben ser deducidas del conjunto del ordenamiento jurídico, lo que rebasa ampliamente el texto constitucional, y por ello no tienen carácter fundamental.

Hemos encontrado algunos ejemplos a lo largo de la Constitución española en que se reconoce a los particulares un poder explícito de hacer y/o no hacer algo. El artículo 11.3 CE dispone que: "En estos mismos países, aun cuando no reconozcan a sus ciudadanos un derecho recíproco, podrán naturalizarse los españoles sin perder su nacionalidad de origen". Aquí hay dos criterios de reconocimiento de derechos, la expresión literal "derecho" y el reconocimiento explícito de un poder-hacer: "podrán". Este doble criterio se sigue también en el artículo 13.4 CE: "La ley establecerá los términos en que los ciudadanos de otros países y los apátridas podrán gozar del derecho de asilo en España" (art. 13.4). En cambio, en el artículo $125 \mathrm{CE}$ se estable un solo criterio, el uso de la expresión "podrán" para reconocer derechos: "Los ciudadanos podrán ejercer la acción popular y participar en la Administración de Justicia mediante la ins-

mente) permitido no expresar su opinión" (R. ALEXY, Teoría de los derechos fundamentales, cit., p. 218).

62 Véase al respecto: J. LÓPEZ HERNÁNDEZ: Lenguaje, normas y sistema jurídico, Tecnos, Madrid, 2012, pp. 150 y ss. 
titución del Jurado, en la forma y con respeto a aquellos procesos penales que la ley determine, así como en los Tribunales consuetudinarios y tradicionales". También el artículo 53.2 CE reconoce el derecho a accionar por la vía del amparo judicial y del recurso de amparo en los supuestos allí previstos: "Cualquier ciudadano podrá recabar la tutela (...)".

Hay supuestos en los que la CE reconoce a los particulares o ciudadanos un poder implícito de hacer y/o no hacer algo. Suelen ir acompañados de un mandato a los poderes públicos, mandato que debe ser entendido como una garantía para el ejercicio del derecho. Así, el mandato de regulación por ley del derecho no debe entenderse como una desconstitucionalización del mismo, sino como una garantía (reserva de ley), pues no tiene sentido mencionar algo en la Constitución para desconstitucionalizarlo. Un ejemplo son los supuestos de las letras a), b) y c) del artículo 105 CE. "La ley regulará": la audiencia de los ciudadanos en el procedimiento de elaboración de las disposiciones administrativas que les afecten; el acceso de los ciudadanos a los archivos y registros administrativos; la audiencia del interesado en el procedimiento administrativo.

En otros supuestos ese poder implícito consiste en participar: la participación de los ciudadanos "en la vida política, económica, cultural y social" (art. 9.2 CE); de la juventud "en el desarrollo político, social, económico y cultural" (art. $48 \mathrm{CE}$ ); de los interesados "en la Seguridad Social y en la actividad de los organismos públicos cuya función afecte directamente a la calidad de vida o al bienestar general" (art. 129.1 CE); de los trabajadores en la empresa (art. 129.2 CE).

A veces ese poder implícito consiste en formas específicas de participación, como la audiencia del art. 105 a) CE, o la de las organizaciones de consumidores y usuarios (art. 51. $2 \mathrm{CE}$ ), como la iniciativa legislativa popular (art. 87.3 CE), o el referéndum consultivo (art. $92 \mathrm{CE}$ ). Estas dos últimas formas han sido incluidas por el Tribunal Constitucional en el derecho a participar en los asuntos públicos del artículo 23.1 CE (STC 119/1995).

\section{REGLA CUATRO: ALLÍ DONDE HAY UN DEBER HACIA UN PARTICULAR, HAY UN CORRELATIVO DERECHO DE ÉSTE}

Dentro de las modalidades de derecho subjetivo, Hohfeld incluye la pretensión (claim), o derecho subjetivo "en sentido limitado y propio" ${ }^{63}$. El derecho de

63 W. HOHFELD, Conceptos jurídicos fundamentales, cit., p. 53.

ISSN: 1133-0937

DOI: https://doi.org/10.20318/dyl.2021.5856
DERECHOS Y LIBERTADES

Número 44, Época II, enero 2021, pp. 277-315 
uno implica el correlativo deber de otro, de modo que: "si $X$ tiene el derecho de excluir a Y de un inmueble del primero, la situación correlativa (y equivalente) es que $Y$ tiene frente a $X$ el deber de permanecer fuera de aquel lugar" ${ }^{\prime \prime}$.

De hecho, cuando el derecho consiste en un permiso o facultad, o en un conjunto de permisos o facultades, entraña también la obligación por parte de los otros (particulares y poderes públicos) de no impedir ni dificultar el libre ejercicio del derecho. Hay que tener presente que el significado de un enunciado normativo no es asertivo sino prescriptivo ${ }^{65}$. Cuando el texto de la Constitución (o de una "declaración" internacional de derechos) dice: "se reconoce el derecho", su significado es "se debe reconocer", es decir, "es obligatorio que se reconozca". La cuestión no es meramente lingüística. En ocasiones, se ha realizado una lectura en clave asertiva o indicativa de enunciados normativos (prescriptivos) y se ha deducido que los términos "se reconoce", "se garantiza", referidos a derechos constitucionales, hacen referencia a derechos preexistentes al Estado y a la Constitución misma: ésta "recono$\mathrm{ce}^{\prime \prime}$ un derecho preexistente. Pero el artículo 43.1 CE dispone que: "Se reconoce el derecho a la protección de la salud". ¿También estaríamos dispuestos a admitir que este derecho de carácter prestacional es anterior al Estado? No se puede realizar una lectura indicativa de enunciados prescriptivos.

Precisamente, del carácter prescriptivo de las normas que reconocen derechos se puede deducir que, con carácter general, todos los derechos fundamentales vinculen de forma negativa a los poderes públicos y a los particulares (deben abstenerse de dificultar o impedir el ejercicio del derecho) y, además, de forma positiva a los poderes públicos, que deben protegerlos ${ }^{66}$. Esta última vinculación positiva se ve claramente en expresiones como "se garantiza", es decir, "es obligatorio que se garantice".

La correlación entre el deber u obligación de uno y el derecho de otro es explicada por García Máynez ${ }^{67}$ mediante la lógica relacional, distinguiendo relaciones entre dos personas $(x$ e $y$ ) a través de los conceptos de deber $u$

64 Ibídem.

65 Sobre los actos de habla y su tipología, véase: J. SEARLE, Actos de habla. Ensayo de filosofía del lenguaje. Traducción de L. M. Valdés Villanueva, Editorial Planeta-De Agostini, Barcelona, 1994.

66 Sobre la doble vinculación de los derechos fundamentales, véase: J. C. GAVARA DE CARA, "La vinculación positiva de los poderes públicos a los derechos fundamentales", Teoría y Realidad Constitucional, núm. 20, 2007, pp. 277-320.

67 E. GARCÍA MÁYNEZ, Lógica del juicio jurídico, Fondo de Cultura Económica, México, 1955, pp. 46-47. 
obligación (que designaremos como $O$ ) y de facultad o derecho (que designaremos como $D$ ). La relación se explica así: $x O y \leftrightarrow y D x$. Es decir, "si y solo si ' $x$ ' tiene un deber (u obligación) respecto de ' $y$ ', entonces ' $y$ ' tiene un derecho o facultad respecto de ' $x$ '”.

Podemos establecer la regla $\mathrm{R} 4:(P y w R y) \wedge R x \wedge y O x \rightarrow x D y$.

Es decir, "Si ' $y$ ' es un poder público [Py] o es un particular [Ry], $y$ ' $x$ ' es un particular $[R x]$ e ' $y$ ' tiene una obligación (constitucional) hacia ' $x$ ' $[y O x]$, entonces ' $x$ ' tiene un derecho (fundamental) contra ' $y$ ' $[x D y]$ ".

La relación entre derecho y deber es recíproca. Del derecho de uno (un particular) nace el deber de otro (un poder público o un particular) y viceversa. Por tanto, basta con identificar, en el texto constitucional, obligaciones de los poderes públicos y/o de los particulares hacia particulares, para deducir de ahí un derecho reflejo ${ }^{68}$.

Hay que matizar que no siempre un deber u obligación implica un correlativo derecho. Por ejemplo, un deber de un particular respecto del Estado (como el deber de pagar tributos) no conlleva, en sentido propio, un derecho de este último respecto de aquél. Por ello hemos circunscrito la regla a supuestos de deberes de los poderes públicos y/o de los particulares hacia particulares ${ }^{69}$.

En todos los supuestos de obligaciones positivas impuestas por la Constitución a los poderes públicos, los particulares también tienen un deber, el deber negativo (pues consiste en una omisión) de abstenerse de interferir o de impedir el ejercicio del correlativo derecho contra el Estado.

No hemos hallado en el texto constitucional muchos supuestos explícitos de obligaciones positivas de unos particulares hacia otros. Un ejemplo lo encontramos en el artículo 39.3 CE: "Los padres deben prestar asistencia de todo orden a los hijos habidos dentro o fuera del matrimonio, durante su minoría de edad y en los demás casos en los que legalmente proceda". De este deber de los padres se infiere el correlativo derecho de los hijos.

68 En efecto, respecto de estos casos, dice Kelsen que: "Si se designa la relación de un individuo, que se encuentra obligado con respecto de otro a determinada conducta, como "derecho", entonces ese derecho no es sino un reflejo de esa obligación" -H. KELSEN, Teoría pura del Derecho, traducción de R. J. Vernengo, UNAM, México, 1982, p. 140.

69 Para un análisis de la relación entre el "derecho contra" y la correlativa "obligación hacia" véase: M. J. ZIMMERMAN, The Concept of Moral Obligation, Cambridge University Press, Cambridge, 1996, pp. 176-180. 
Sin embargo, son mucho más frecuentes los supuestos de obligaciones impuestas con carácter genérico (aunque sus principales sujetos obligados son los poderes públicos), o como expresos mandatos a estos últimos.

Ejemplos en la Constitución española son: "Los españoles son [es decir, deben ser] iguales ante la ley (...)" (art. 14 CE). Este precepto establece una obligación positiva dirigida a los poderes públicos, especialmente los poderes ejecutivo y judicial, en relación con los particulares, y, por consiguiente, un derecho correlativo de éstos. Incluso un enunciado aparentemente anodino como el del artículo 5 CE - "La capital del Estado es [debe ser] la villa de Madrid" - daría derecho, en caso de incumplimiento, a los vecinos de dicha ciudad, a reclamar ante los tribunales la capitalidad. Otros supuestos son: art. 17.2 CE: "El detenido deberá ser puesto en libertad..."; art. 17. 3: "Toda persona detenida deberá ser informada (...)"; art. 18.2: "el domicilio es inviolable"; art. 27.4: "la enseñanza básica es obligatoria y gratuita" (art. 27.4); en relación con el derecho a la tutela judicial efectiva, "la justicia será gratuita (...) (art. 119 CE); las actuaciones judiciales serán públicas (...) (art. 120.1); “el procedimiento será predominantemente oral" (art. 120.2); "las sentencias serán siempre motivadas y se pronunciarán en audiencia pública” (art. 120.3). Todas estas obligaciones van dirigidas a los poderes públicos, son mandatos implícitos a los poderes públicos.

Pero también hay en la Constitución mandatos explícitos a los poderes públicos, incluidos muchos de ellos dentro del Capítulo III del Título I, sobre "Los principios rectores de política social y económica". Al menos algunos de estos mandatos pueden ser interpretados como deberes de los poderes públicos hacia los ciudadanos o particulares, deberes de los que dimanan auténticos derechos constitucionales, y por tanto, derechos fundamentales, que consisten en la pretensión de exigir que los poderes públicos hagan algo (lo que estipule el precepto constitucional) para proteger a -o en beneficio dedeterminadas personas o grupos de personas.

Cuando la Constitución establece mandatos explícitos a los poderes públicos en general, o al legislador, en relación con derechos fundamentales ya identificados en virtud de reglas anteriores, puede entenderse que tales mandatos entrañan obligaciones por parte de los poderes públicos, y forman parte de las garantías o incluso del contenido de los derechos ${ }^{70}$.

70 En este sentido, G. ESCOBAR ROCA, “Presupuestos estructurales”, cit., 306. Sin embargo, no siempre el TC ha interpretado tales mandatos como formando parte del contenido, 
Ejemplos de estos supuestos son los artículos: 13.4 ("la ley establecerá" en relación con el derecho de asilo); 16.3 (obligaciones de los poderes públicos en relación con la libertad religiosa); 17.4 (la ley regulará (en relación con el procedimiento de habeas corpus); 17.4 (" por ley se determinará el plazo máximo de duración de la prisión provisional"); 18.4 ("la ley limitará el uso

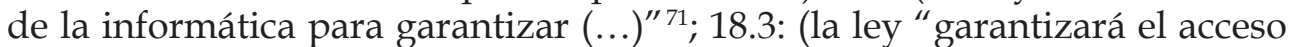
a dichos medios (medios de comunicación social públicos) de los grupos sociales y políticos significativos", en relación con las libertades de expresión y de información); 32.2 CE: ("la ley regulará", en relación con el derecho a contraer matrimonio); 30.2 (la ley regulará la objeción de conciencia...). Otros ejemplos de mandatos a los poderes públicos que van referidos a derechos fundamentales ya previamente identificados en la Constitución de acuerdo con otras reglas interpretativas son los contenidos en los artículos 27, 43, 44, 45 y 47. También los mandatos relacionados con poderes implícitos reconocidos a los particulares en los artículos 9.2 (en relación con la libertad e igualdad efectivas y con la participación), 48 (en relación con el derecho a la participación de la juventud), 51.2 (en relación con los derechos de los consumidores y usuarios), 87.3 (en relación con el derecho participación mediante iniciativa legislativa popular), 92 (en relación con el derecho de participación en el referéndum consultivo), 105 (letras a, b y c), 129.1 (en relación con el derecho de participación de los interesados en la Seguridad Social y en los organismos públicos) y 129.2 (en relación con el derecho de los trabajadores a participar en la empresa).

Más dificultades se plantean cuando la Constitución establece mandatos a los poderes públicos en enunciados en los que no se han identificado derechos con arreglo a reglas anteriores. Los principales obligados por tales mandatos son los poderes legislativos del Estado y/o de las Comunidades autónomas $^{72}$, de acuerdo con el sistema constitucional de reparto de competencias; y en segundo lugar, los poderes ejecutivos de los distintos entes territoriales, según sus competencias y atribuciones.

Podríamos entender que dichos mandatos a los poderes públicos, en relación con particulares o en beneficio de particulares, cuando no son mandatos excesivamente genéricos (como el del primer enunciado del art. $40.1 \mathrm{CE}$ ), son

o de las garantías del derecho. Así, el TC no considera como derecho fundamental las ayudas a los centros docentes (STC 86/1985, de 10 de julio, FJ. 3).

71 En este precepto el TC ha visto un derecho: STC 254/1993, de 20 de julio, FJ 6.

72 En este sentido, J. R. COSSÍO DÍAZ, Estado social y derechos de prestación, cit., p. 270. 
deberes de los poderes públicos hacia los particulares e implican, en consecuencia, correspondientes derechos constitucionales de éstos. Pero, al menos en relación con los mandatos contenidos en el Capítulo III, esta interpretación choca con el artículo 53.3 CE, que impide que los mandatos (principios rectores) puedan ser alegados directamente ante los tribunales, sin ley de desarrollo, como derechos constitucionales.

Para salvar este escollo, otra opción es entender, como hemos hecho al interpretar el artículo 53.3 CE, que los mandatos a los poderes públicos del Capítulo III, cuando tienen por finalidad hacer efectivos o garantizar derechos de los ciudadanos (es decir, son mandatos en relación con particulares o en beneficio de particulares), aunque no son en sí mismos derechos, presuponen la existencia del derecho constitucional que tratan de hacer efectivo. Dicho derecho (normalmente de prestación) es mencionado en la Constitución, aunque no se utilice explícitamente la palabra derecho (es un derecho implícito). Estos derechos podríamos incluirlos también en la Regla R3, aunque, al tener un carácter prestacional, no consisten en un derecho a hacer, sino a que otros (los poderes públicos) hagan ${ }^{73}$. El poder que reconocen es el de exigir que otros hagan.

Aunque habría que examinarlo caso por caso, podemos poner algunos ejemplos. El art. 39.2 CE dispone que: “La ley posibilitará la investigación de la paternidad". Aquí podríamos reconocer un derecho a "la investigación de la paternidad". Respecto del mismo, la ley tiene la obligación de facilitar tal investigación. El art 40.2 CE establece que los poderes públicos "velarán por la seguridad e higiene en el trabajo y garantizarán el descanso necesario, mediante la limitación de la jornada laboral, las vacaciones periódicas retribuidas y la promoción de centros adecuados". Aquí los derechos constitucionales que se pretenden garantizar son la seguridad e higiene en el trabajo y el descanso laboral. Aunque el artículo 41 se ha entendido por el TC como una garantía institucional, en él es identificable un derecho de

73 Alexy incluye los derechos de prestación en sentido estricto dentro de la categoría más amplia de derechos a acciones positivas del Estado, que incluye también los derechos a protección y los derechos a organización y procedimiento -R. ALEXY, Teoría de los derechos fundamentales, cit., pp. 419 y ss-. Para Alexy, "los derechos a prestaciones en sentido estricto son derechos del individuo frente al Estado a algo que -si el individuo poseyera medios financieros suficientes y si encontrase en el mercado una oferta suficiente- podría obtenerlo también de particulares. Cuando se habla de derechos sociales fundamentales, por ejemplo, del derecho a la previsión, al trabajo, la vivienda y la educación, se hace primariamente referencia a derechos a prestaciones en sentido estricto" (cit., p. 482). 
los ciudadanos a "la asistencia y prestaciones sociales suficientes ante situaciones de necesidad, especialmente en caso de desempleo", que los poderes públicos deben garantizar manteniendo un "régimen público de Seguridad Social". En el artículo 49 puede verse un derecho de "los disminuidos físicos, psíquicos y sensoriales" a la "atención especializada que requieran", la cual deberá ser prestada por los poderes públicos, así como a su "tratamiento, rehabilitación e integración". En el artículo 50 se identifica un derecho a "la suficiencia económica" de los ciudadanos durante la tercera edad, que "los poderes públicos garantizarán, mediante pensiones adecuadas y periódicamente actualizadas". En el artículo 51.1 CE es identificable un derecho de los consumidores y usuarios a su defensa, que debe ser garantizado por los poderes públicos.

Fuera del Capítulo III, el artículo 129 CE dispone que los poderes públicos "también establecerán los medios que faciliten el acceso de los trabajadores a la propiedad de los medios de producción". Si se observa, aquí se trata de un derecho ya previamente reconocido por la Constitución: la propiedad (art. 33.1 CE), solo que sobre un bien concreto: "los medios de producción". Sin embargo, el artículo 129.2 CE obliga a los poderes públicos (incluyendo al legislador) hacia los trabajadores, y por tanto, reconoce un correlativo derecho (fundamental) de éstos contra los poderes públicos competentes, a que establezcan los medios que les faciliten el acceso a ese tipo de propiedad ${ }^{74}$.

Salvo lo que hemos señalado más arriba, sobre las dificultades, en defecto de ley reguladora, de la tutela judicial efectiva de los derechos de prestación, o de configuración legal en general, no es objeto de este estudio la exigibilidad de tales derechos en caso de incumplimiento de los correlativos deberes constitucionales por omisión del poder legislativo o del poder ejecutivo $^{75}$.

74 Sobre este último enunciado del artículo 129 CE, véase: A. COLOMER VIADEL, "Regulación constitucional de la participación de los trabajadores en la economía y en la empresa", UNED. Revista de Derecho Político, núm. 100, 2017, pp. 831-848, esp., pp. 842 y ss.

75 Sobre este asunto, véase: M. GÓMEZ PUENTE, La inactividad del legislador: una realidad susceptible de control, McGraw-Hill, Madrid, 1997; I. VILLAVERDE MENÉNDEZ, La inconstitucionalidad por omisión, McGraw-Hill, Madrid, 1997; J. J. FERNÁNDEZ RODRÍGUEZ, La inconstitucionalidad por omisión. Civitas, Madrid, 1998; J. C. GAVARA DE CARA, “La vinculación positiva de los poderes públicos a los derechos fundamentales", cit., p. 280 y ss.; G. ESCOBAR ROCA, “Presupuestos estructurales”, cit., pp. 693-711.

ISSN: 1133-0937

DOI: https://doi.org/10.20318/dyl.2021.5856
DERECHOS Y LIBERTADES

Número 44, Época II, enero 2021, pp. 277-315 


\section{REGLA DERIVADA 4.1: LA DEDUCCIÓN DE UN DERECHO A PARTIR DE UNA PROHIBICIÓN}

La regla R4 es perfectamente aplicable a las prohibiciones constitucionales. Esto es así porque la prohibición de hacer algo es equivalente a la obligación de no hacerlo, lo cual se puede expresar del siguiente modo: $V p \leftrightarrow O \sim$ $P$. Es decir, $p$ está vetado (prohibido) si y solo si es obligatorio no $p$.

La regla R4 puede ser reformulada para las prohibiciones del siguiente modo:

$$
\text { RD 4.1: }(P y w R y) \wedge R x \wedge y O x(y(\sim p)) \rightarrow x D y(y(\sim p)) .
$$

Es decir, "Si ' $y$ ' es un poder público [Py] o un particular [Ry], $y$ ' $x$ ' es un particular [Rx] e ' $y$ ' está obligado frente a ' $x$ ' a que ' $y$ ' no haga ' $p$ ' [yOx (y ( p p))], entonces ' $x$ ' tiene el derecho frente a ' $y$ ' a que ' $y$ ' no haga ' $p$ ' $[x D y(y(\sim p)) \text {. }]^{\prime \prime}$.

Son numerosas las prohibiciones constitucionales de las que se deducen derechos fundamentales. Por ejemplo, tienen significado de prohibiciones de las que se deducen derechos las expresiones contenidas en los siguientes preceptos: 11.2 CE (prohibición de privación de nacionalidad a los españoles de origen); 14 (prohibición de discriminación); art. 15 (prohibición de tortura y de penas o tratos inhumanos o degradantes)"; 15 (prohibición de la pena de muerte); 16.2 (prohibición de ser obligado a declarar sobre la ideología, religión o creencias); 16.3 (prohibición del carácter confesional del Estado); 17.1 (prohibición de privación de libertad); 17.2 (prohibición de duración de la detención preventiva más allá de lo indicado en el precepto); 18.2 (prohibición de entrada o registro en domicilio); 19, último inciso (prohibición de limitar por motivos ideológicos o políticos el derecho a entrar y salir libremente de España); 20.2 (prohibición de censura previa); 20.5, a contrario sensu (prohibición de secuestro administrativo de publicaciones); 21.2, respecto de la prohibición de reuniones, a contrario sensu; 22.2 (prohibición de asociaciones que persigan fines o utilizan medios tipificados como delitos); 22.4, a contrario sensu (prohibición de suspensión o de disolución administrativa de asociaciones); 22.5 (prohibición de las asociaciones secretas y de carácter paramilitar); 25.1 (principio de legalidad penal); art. 25.2 (prohibición de trabajos forzados); 25.3 (prohibición a la administración civil de imponer sanciones que impliquen privación de libertad); 26 (prohibición de los tribunales de honor); art. 31.3 (prohibición de establecer prestaciones personales 
o patrimoniales de carácter público por normas de rango inferior a la ley); 33.3 (prohibición de privación de bienes y derechos, salvo que se reúnan los requisitos previstos en el precepto); y 117.6 (prohibición de los tribunales de excepción).

\section{CONCLUSIONES}

En este estudio hemos pretendido, más que identificar todos y cada uno de los derechos fundamentales existentes en la Constitución española, ofrecer unas pocas reglas interpretativas que permitan contribuir a su identificación, mostrando numerosos ejemplos de aplicación de cada regla.

Lo primero era, pues, fijar un concepto formal de derecho fundamental. Así, mediante la primera regla interpretativa (R1) hemos establecido una ecuación entre derecho constitucional y derecho fundamental.

A partir de ese momento sólo quedaba identificar los derechos fundamentales en la Constitución española. La identificación de los derechos fundamentales es una cuestión lógicamente previa a la de su clasificación, o al examen de sus garantías. En cambio, en gran parte de la doctrina se ha partido del sistema de garantías diseñado en la Constitución, en especial en el artículo 53, para determinar si algo es un derecho fundamental o no. Esta subversión del orden lógico de las cuestiones sobre derechos fundamentales conduce a conclusiones contradictorias con la regla R1, como la afirmación de que existen derechos constitucionales no fundamentales. La identificación de los derechos fundamentales es incluso previa al examen de otros aspectos como su naturaleza jurídica, titularidad, contenido y límites.

Para proceder a dicha identificación, hemos partido de la regla interpretativa R2, que viene a decir que "si la Constitución califica algo como derecho, entonces es un derecho constitucional", y por tanto, conforme a la regla $\mathrm{R} 1$, fundamental. La regla R2, basada en una interpretación literal de los términos usados por la Constitución, es una base sólida para identificar derechos fundamentales a lo largo de todo el texto constitucional, no sólo en el Capítulo II del Título I, sino también en los Capítulos I y III, e incluso fuera del Título I. Cualquier enunciado constitucional que aparentemente se oponga a esta regla debe ser interpretado conforme a la misma.

En concreto, se ha argumentado que no existen derechos fundamentales en el Capítulo III del Título I, sobre los "principios rectores de la política 
social y económica", en contra de la evidente expresión literal de algunos de los enunciados de ese capítulo, y en base a determinada interpretación de los enunciados de los artículos 53.1 y 53.3 CE. Así, se ha sostenido que solo los derechos del Capítulo II disponen de un contenido esencial que el legislador debe respectar, y, por tanto, sólo esos derechos son fundamentales. Pero esta interpretación del artículo 53.1 CE entra en abierta contradicción con las reglas interpretativas R1 y R2. Por el contrario, hemos sostenido, en base a argumentos que no es preciso reproducir ahora, que el contenido esencial de un derecho es lo mismo que su contenido constitucional, y que, por tanto, todos los derechos constitucionales poseen un contenido esencial a respetar por el legislador, sea cual sea su ubicación en el texto de la Constitución.

Hemos interpretado de forma restrictiva el obstáculo que representa el artículo 53.3 CE, en concreto el enunciado que dice que los principios reconocidos en el Capítulo III "sólo podrán ser alegados ante la jurisdicción ordinaria de acuerdo con lo que dispongan las leyes que los desarrollen". Tal precepto debe aplicarse solo a los principios rectores (mandatos a los poderes públicos), pero no a los derechos reconocidos literalmente en dicho Capítulo. De este modo, hemos removido los obstáculos que representan algunas interpretaciones de los artículos 53.1 y 53.3 CE para afirmar la existencia de derechos fundamentales en el Capítulo III, y en general, fuera del Capítulo II del Título I.

Pero las reglas R1 y R2, aunque importantes, no son suficientes para identificar todos los posibles derechos fundamentales del texto constitucional. Era preciso aportar otras reglas. Para ello nos hemos basado en la lógica jurídica y en el concepto de derecho subjetivo.

La regla R3 se basa en el concepto de permisión, como poder de hacer o no hacer algo, que se contrapone, en lógica deóntica, a la prohibición de hacer o no hacer algo. Las normas que atribuyen derechos se incluyen dentro de las normas permisivas. Así pues, si hay una norma constitucional que atribuye, de forma explícita o implícita, un poder o facultad a un particular entonces le está atribuyendo un derecho. Esto viene a decir la regla R3, que nos ha permitido identificar otros derechos fundamentales a lo largo del texto constitucional.

Para la regla interpretativa $\mathrm{R} 4$ (la regla $\mathrm{R} 4.1$ no es más que una derivación de la regla R4, aplicada a las prohibiciones), hemos partido de la correlación lógica entre derechos y deberes, de modo que, si existe en el texto cons- 
titucional un deber hacia un particular (ya sea un deber de un poder público o de otros particulares), allí existe un derecho fundamental.

En este sentido, los mandatos explícitos a los poderes públicos en relación con los particulares (o en beneficio de particulares), cuando no son excesivamente genéricos, pueden ser interpretados como deberes de los poderes públicos hacia los particulares, y, en consecuencia, presuponen correlativos derechos de éstos. De este modo, se da la vuelta a la interpretación habitual de los "principios rectores" del Capítulo III, según la cual la calificación de algo como "principio rector" (usualmente un mandato a los poderes públicos) se ha usado para negar la existencia un derecho subjetivo y no para reconocer un derecho fundamental preexistente que el mandato a los poderes públicos pretende hacer efectivo.

En definitiva, de acuerdo con las reglas que hemos visto, hay derechos fundamentales no sólo en el Capítulo II del Título I de la Constitución, sino también en el Capítulo III, en el Capítulo I, e incluso fuera del Título I. Como hemos dicho, el carácter fundamental de los derechos identificados tiene importantes consecuencias normativas: vinculan a todos los poderes públicos, incluidos el legislador y el poder judicial. En teoría, todos ellos pueden ser alegados directamente ante los tribunales, pero los derechos de configuración legal, para su efectividad, precisan de desarrollo legislativo.

Las reglas interpretativas seleccionadas en este trabajo tienen especial importancia para identificar derechos sociales de carácter fundamental sin necesidad de proceder a reformar la Constitución, salvo que el objeto de la reforma sea mejorar su nivel de protección constitucional. Aunque las hemos aplicado solamente al texto de la Constitución, las referidas reglas de identificación de derechos, en especial las reglas R2, R3, R4 y R4.1 pueden ser aplicadas a cualquier texto constitucional, legislativo o convencional.

Antonio IbÁÑez Macías Universidad de Cádiz Facultad de Derecho Campus Universitario de Jerez Avda. de la Universidad, núm. 4, 11406, Jerez de la Frontera, Cádiz.

e-mail:antonio.ibaniez@uca.es 